AperTO - Archivio Istituzionale Open Access dell'Università di Torino

\title{
Multiscale geophysical characterization of an unstable rock mass
}

\section{This is the author's manuscript}

Original Citation:

Availability:

This version is available http://hdl.handle.net/2318/1616367

since 2017-05-15T13:05:06Z

Published version:

DOI:10.1016/j.tecto.2016.02.045

Terms of use:

Open Access

Anyone can freely access the full text of works made available as "Open Access". Works made available under a Creative Commons license can be used according to the terms and conditions of said license. Use of all other works requires consent of the right holder (author or publisher) if not exempted from copyright protection by the applicable law. 
This Accepted Author Manuscript (AAM) is copyrighted and published by Elsevier. It is posted here by agreement between Elsevier and the University of Turin. Changes resulting from the publishing process - such as editing, corrections, structural formatting, and other quality control mechanisms - may not be reflected in this version of the text. The definitive version of the text was subsequently published in TECTONOPHYSICS, 675, 2016, 10.1016/j.tecto.2016.02.045.

You may download, copy and otherwise use the AAM for non-commercial purposes provided that your license is limited by the following restrictions:

(1) You may use this AAM for non-commercial purposes only under the terms of the CC-BY-NC-ND license.

(2) The integrity of the work and identification of the author, copyright owner, and publisher must be preserved in any copy.

(3) You must attribute this AAM in the following format: Creative Commons BY-NC-ND license (http://creativecommons.org/licenses/by-nc-nd/4.0/deed.en), 10.1016/j.tecto.2016.02.045

The publisher's version is available at:

http://www.sciencedirect.com/science/article/pii/S0040195116001529

When citing, please refer to the published version.

Link to this full text:

http://hdl.handle.net/ 


\section{INTRODUCTION}

Unstable rock masses can represent a serious threat to highly populated areas and can cause relevant damages. In order to effectively mitigate the hazard from rock mass instabilities, a detailed knowledge of the inner structure and of the physico-mechanical properties of the involved rock volume is required to forecast the localization of deformation and the pre-failure mechanisms.

The fracturing assessment, with particular reference to orientation, spacing, opening, filling and hydraulic properties of the discontinuities is key to determine geometry, location and orientation of potential sliding surfaces leading to rockfalls and landslides. Geological and geomechanical studies, remote sensing and aerial techniques can be used for this aim on the external surfaces of the studied medium. Geophysical methods are however the best approach to image the internal structure of the rock mass, undetectable with a comparable resolution by other techniques, thus providing valuable constraints on the physical state inside the medium. A review of the geophysical methods applied to the internal characterization of landslides and rockslides can be found in Bogoslovsky and Ogilvy (1977), Jongmans and Garambois (2007) and in Maurer et al. (2010). Successful results are documented from seismic methods, such as reflection, refraction, tomography and ambient noise measurements, electrical methods, such as electrical resistivity tomography (ERT) and spontaneous potential (SP), and electromagnetic methods, such as ground-penetrating radar (GPR).

Electrical methods provide important information about the water/fluid saturation, since electrical resistivity is strongly influenced by the water content and its conductivity, 
as well as the fracturing state; GPR can be useful to obtain an high-resolution imaging of fractures when the investigated rock mass allows a sufficient depth of penetration. However, among the available geophysical methods, seismic surveys are often most suitable to infer the internal structure of the potentially unstable body, also because the measurements are directly related to the mechanical properties of the rock mass (density and deformation moduli) and more valuable for numerical simulation of the slope stability. Seismic data are also fundamental for the definition of a reliable velocity field to be used in microseismic monitoring applications.

Bruno and Mariller (2000) tested high-resolution seismic reflection surveys combined with other geophysical tests on a landslide in the Swiss Alps. Their methodology allowed the identification of the slip surface within a gypsum layer located at the depth of $50 \mathrm{~m}$. Mauritsch et al. (2000) applied seismic refraction methods for the investigation of a large Alpine gravitative sliding in southern Austria, affecting slopes with a complex fabric given by limestones, dolomitic conglomerates, sandstones and shales. The variations in the P-wave velocity were interpreted as lithological changes and seismic data supported in the determination of the stable bedrock.

Over the last decades, geophysical tomographic imaging has considerably grown, allowing to obtain 2-D or 3-D imaging of the analyzed medium, through inversion procedures. This technique was used by Jongmans et al. (2000) and Méric et al. (2005) showing a significant decrease in the P-wave velocity near the failure surface within the unstable mass. 
Here we carried out a seismic cross-hole survey to characterize the unstable granitic cliff of Madonna del Sasso (NW Italy). During the survey, seismic sources were located both in well and at surface, as well as the receivers. The travel times of the first arrivals among different source-receiver separation were then used to produce a tomographic velocity cross-section of the subsurface between the two boreholes (Bregman et al., 1989; Calnan and Schuster, 1989; Chen et al., 1990, Lines and LaFehr, 1989; McMechan et al., 1987). Cross-hole tomography is a very suitable methodology for our purposes because is expected to provide higher resolution imaging with respect to surfacebased methods, since the energy does not travel through the highly-attenuating near surface and the travel distances are shorter. In addition, the resolution of cross-hole tomography is not depth-limited since the majority of the energy travels between the wells so that a trans-illumination of the imaged medium can be achieved. This is even more important in a highly fractured medium, as the one object of the study, where waves travel along complex paths that could be hidden if only surface measurements are available.

Geophysical field data can be integrated by laboratory surveys to establish a link between rock properties and geophysical data. Heincke et al. (2006) applied 3-D seismic tomography to an unstable Alpine mountain slope, finding significantly lower apparent velocities in the field compared to the average ones determined from laboratory analyses of intact rocks collected at the investigated site. The gap has been interpreted as due to the widespread presence of dry cracks, fracture zones and faults at different scales.

Ultrasonic pulse velocity measurements have been widely applied on granite samples since the elastic-wave velocity is significantly affected by the volume, 
distribution and shape of rock pore space and it is well known that elastic wave velocities are substantially reduced in the presence of thin cracks (Benson et al., 2007; Hadley, 1976; Stanchits et al., 2006). Vasconcelos et al. (2008) carried out P-wave ultrasonic velocity measurements on granite specimens with different size and shape, presenting statistical correlations with physical (density, porosity) and mechanical properties (modulus of elasticity, compressive and tensile strength). Weathering and moisture were found to significantly affect the values of ultrasonic pulse velocity. Chaki et al. (2007) investigated the decrease in the ultrasonic pulse velocities versus increasing heat treatment temperature in granites, interpreted as an effect of micro-cracking due to thermal treatment, in agreement with the results obtained for other igneous rocks (Vinciguerra et al., 2005). Cerillo et al. (2014) investigated the correlations between physico-mechanical properties of granite samples and new parameters related to Fast Fourier Transform (FFT) and attenuation, obtained from the ultrasonic evaluation, in addition to ultrasonic pulse velocity. These additional correlations strengthen the use of ultrasonic tests as a nondestructive useful method for granite physical and mechanical characterization.

Proper correlation of seismic velocities obtained at the field scale (1 to $100 \mathrm{~Hz})$ with ultrasonic velocities at the laboratory scale $(10 \mathrm{kHz}$ to $1 \mathrm{MHz})$ has to be performed considering both the difference in the frequency range at which tests are executed and the investigated volume. Ciccotti and Mulargia (2004) showed that ultrasonic measurements in the $\mathrm{kHz}$-to-MHz regime can determine about $10 \%$ overestimation of elastic moduli with respect to measurements carried out in the $0.01-$ to- $20-\mathrm{Hz}$ range. At low frequency fluid pressure is equilibrated in pores and cracks, while at higher frequencies, the fluid has no 
time to flow and the fluid pressure is not equilibrated (O'Connel and Budiansky, 1976). This frequency-dependent behavior produces a dispersion which is experimentally observed in isotropic media and is generally called squirt-flow mechanism (Mavko and Nur, 1975; Thomsen, 1985). Dispersion is believed to drop off rapidly to less than $10 \%$ when effective pressure is increased (Zamora et al., 1994, and references therein), but this is strongly influenced by the density of cracks (Schubnel and Gueguen, 2003, and references therein) in the rock. Despite these limitations, ultrasonic measurements reliably approximate the seismic measurements performed on the field and are helpful for the lithological interpretation and the cross-check of the field-scale measurements.

Laboratory ultrasonic measurements were therefore also performed in this study to lithologically interpret the seismic tomography carried out at the field scale and for transferring the microscopic knowledge at rock sample level to the field scale rock mass. Rock samples were systematically collected at the site in order to take into account velocity differences deriving from the high level of variability and alteration within the unstable cliff. Other granite samples were also collected at the site for physical (density and porosity) and mechanical characterization (Uniaxial Compressive Strength from Point Load tests). Correlation between these laboratory parameters and the seismic velocity were then investigated. Results from different scales of study (field and laboratory) were finally compared with previous geological surveys (stratigraphic logs of continuous core drillings, geomechanical studies on the overall fracturing state) to provide a complete model of the studied rock mass. 


\section{TEST SITE}

The cliff of Madonna del Sasso $\left(45^{\circ} 79^{\prime} \mathrm{N}, 8^{\circ} 37^{\prime} \mathrm{E}\right.$ ) is located in NW Italy, on the western shore of the Orta Lake (Fig. 1a). It is a massive granite outcrop bordered on three sides (N, E and S) by pseudo vertical walls, with a height of about $200 \mathrm{~m}$ (Fig. 1b). The actual steep and complex morphology derives from the intense mining activity lasting until a few decades ago, on the bottom of the cliff. At the top of the cliff a panoramic square is found at approximately $650 \mathrm{~m}$ a.s.1., in front of the XVIII-century sanctuary from which the place takes its name. At the bottom of the slope, between the cliff and the lake, there are several buildings, including houses and small factories, and a road (SP 46) connecting the towns on the western shore of the lake.

From a geological point of view, the area is totally characterized by a granitic rock mass, known as Granito di Alzo. This unit belongs to the non-metamorphosed, and generally low deformed, granitic masses, related to a late-Hercynian magmatic intrusion (lower Permian), that outcrops along the contact between the lithologies of the Serie dei Laghi and the Ivrea-Verbano Zone (Boriani et al., 1992; Giobbi Origoni et al., 1988). These granites, commonly known as Graniti dei Laghi, make a large batholith, elongated in NE-SW direction, which includes five large magmatic intrusions, among which the Alzo-Roccapietra Pluton, of granitic and granodioritic composition, outcropping between the lower Sesia Valley and the Orta Lake.

Since 1981 warnings related to movements and cracks opening observed at the panoramic square were reported by the local authorities. During the same year, 5 continuous core drillings were performed at the site and three of them (S1, S2 and S5) 
were equipped with a 30-meter-length aluminium casing for inclinometric monitoring. Inclinometric measurements were acquired two times per year until 1990, when a further episode of displacement damaged the hole casings. Inclinometric recordings revealed moderate displacements, up to a maximum of $10 \mathrm{~mm}$ on the horizontal plane in 6 months (Regione Piemonte, 1993).

A geomechanical characterization of the site (Lancellotta et al., 1991) led to define the rock mass as intact or massive but affected by widely spaced discontinuities with good surface quality. Four main joint sets were identified (dip direction/dip): K1 (110/75), K2 (0/80), K3 (150/15) and K4 (50/75). These discontinuities (Fig. 2) tend to isolate two frontal portions of the cliff which increase their instability depending upon the rock joints along the fractures and the foot edge. A volume of about $12,000 \mathrm{~m}^{3}$ has been estimated forming the most instable sector at the north-eastern limit of the cliff, bordered by fractures $\mathrm{K} 2$ and $\mathrm{K} 4$ (or K1) on the sides and probably truncated at the bottom by K3 system (sector A in Fig. 2). South to this sector, a second block was identified (sector B in Fig. 2), delimited by fractures $\mathrm{K} 4$ and $\mathrm{K} 2$ on the sides and $\mathrm{K} 3$ at the base, with a volume of about $7,500 \mathrm{~m}^{3}$. Particularly along the major $\mathrm{K} 4$ discontinuity there is a clear evidence of displacement: a visible decimetric step dislocates the lawn and the confining walls of the panoramic square. On the other hand, K2 major fracture seems to show the widest opening (around $40 \mathrm{~cm}$ ) with a significant persistence within the rock mass and apparently no filling material in the first superficial meters of observation.

After this study, a network of 10 automatic crackmeters coupled with temperature probes was installed for the displacement monitoring of sector A. Five sensors were 
deployed on the northern side, following the K4 fracture, and the other were placed on the southern cliff following K2 fracture at different heights. The monitoring suggested that the joint opening is directly connected to the mean air temperature and displacements are interpreted as the outcome of rock-mass thermal contraction, with a maximum displacement over the winter, and a minimum over the summer, related to thermal expansion. This positive and negative peaks are followed by gradual closing (in spring) and opening (in autumn) trends. At the end of an annual cycle of observation three probes went back to the initial zero-value while 7 sensors preserved a residual opening of an average of $2 \mathrm{~mm} /$ year. A differential behaviour in the displacement curves was also detected: the maximum opening values were recorded at the highest probes (5-6.1 $\mathrm{mm} /$ year), suggesting a foot control of the block on displacements (Regione Piemonte, 1993). From 2006, Arpa Piemonte started a topographic monitoring of the site. In 2007, two wire strain gauges were installed on the top yard, on fracture K4. They were discontinuously operating till July 2009, when the monitoring system was destroyed by lightening. The available data for that period confirm the seasonal fluctuation of opening and closing of the fractures.

Even if, up to now, relevant irreversible changes have not been detected by the various adopted monitoring systems, there is an increasing awareness in population of the risk related to the site, particularly in occasion of isolated phenomena (winter 2013, spring 2015) when, after long-lasting intense rainfalls, several damages and confined collapses occurred in the grassy yard at the top of the cliff, bringing to light the deep and open chasms related to fractures of the $\mathrm{K} 4$ and $\mathrm{K} 2$ systems. 
With this aim, early warning systems based on microseismic monitoring could be potentially helpful in forecasting the growth of fractures and minimizing potential damage. For this reason a microseismic monitoring network was deployed at the site in 2013. To this aim, a complete seismic characterization of the site became a key factor for choosing the best node position for the system. Moreover, working with a small heterogeneous volume with a sharp topography and several open fractures, a detailed seismic velocity model of the investigated medium is required for improving the location of the detected microseismic events within the rock mass.

\section{MATERIALS AND METHODS}

\subsection{Field seismic surveys}

Geophysical testing at the top of the granitic cliff was difficult. Even if the top of the cliff is easily accessible, the limited available space does not allow the deployment of long arrays. Moreover the sharp and complex morphology of the site, along with the expected heterogeneous velocity field, due to the highly fractured medium, can cause strong scattering and attenuation of seismic waves. The choice of cross-hole seismic tomography, taking advantage of the existing inclinometric drillings (S1, S2 and S5 - Fig. 3a), appeared the only way to investigate at depth such a structural setting. Two subsequent cross-hole tests were performed, the first between S1 and S2 (distance = 13 $\mathrm{m}$ ) and the second between S1 and S5 (distance = $18.7 \mathrm{~m}$ ). Results were grouped after the individual acquisition of the two separate surveys. 
A Borehole Impacter Source by Geotomographie GmbH was used as in-hole source in the $\mathrm{S} 2$ borehole, with three different locations down to a depth of $5 \mathrm{~m}$. At this depth an obstruction of the hole casing, probably due to the rock mass displacement, inhibited deeper measurements. On the yard surface, a sledge hammer, impinging both vertically and horizontally on a steel rod, provided the surface source for P- and SH-wave generation, in different locations along the lines connecting the three holes. For SH waves, source polarity inversion was used for a better identification of first arrivals. A prototype string equipped with 8 three-component geophones $(10 \mathrm{~Hz})$ at $1 \mathrm{~m}$ spacing, stiffly connected by an aluminium bar that controls the orientation of the geophones in the borehole, was progressively lowered (with superposition of 1 or 2 geophones at each subsequent positioning) in the boreholes, till the maximum available depth (respectively of $27 \mathrm{~m}$ and $21 \mathrm{~m}) .4$ three-component geophones $(2 \mathrm{~Hz})$ were placed along the lines connecting the three boreholes at surface on the lawn, with a spacing of $2.5 \mathrm{~m}$ (along S1S2) and $4 \mathrm{~m}$ (along S2-S5). Figure 3b briefly summarize the used source and receiver positions.

From each source location a fan of seismic rays was emitted towards each in-hole or surface detector. Consecutive fans were obtained by shifting the array of detectors along the borehole (S2 and S5) and shooting the source several times for each position in S1. When the available positions for detectors were completed, the source was moved and the procedure was repeated. The reconstruction of the complete seismograms was obtained merging the recordings (consecutive in-hole descents and surface traces) derived from the same shot position (Fig. 4). 
Seismic traces were recorded with a window length of $500 \mathrm{~ms}$ and a sampling interval of $31.2 \mu \mathrm{s}$. For each shot, more than 10 recorded traces were stacked in order to improve the signal-to-noise ratio. First-arrival-time manual picking was performed on the acquired seismic traces, to obtain both $\mathrm{P}$ - and $\mathrm{SH}$-wave velocities. The surface shots closest $(1.5 \mathrm{~m})$ to S1 (reconstructed seismograms in Fig. 4) and to S5 (2 m) were initially processed as a traditional down-hole test in order to directly compare the resulting P-and SH-wave velocity profiles with the available core loggings and RQD profiles derived from the continuous core drillings. In addition to these two surveys, traditional refraction tomography surveys were also executed, approximately on the same line connecting the three inclinometric boreholes, using: 48 vertical geophones $(4.5 \mathrm{~Hz})$ with $75-\mathrm{cm}$ spacing for $\mathrm{P}$ waves and 24 swyphones ${ }^{\mathrm{tm}}$ with $1.5 \mathrm{~m}$ spacing for $\mathrm{SH}$ waves, in order to achieve the seismic velocity field over the shallower structure and to build a reliable initial model for the inversion of cross-hole results.

All the arrival times, from surface and in-hole shots, were then inverted to achieve a tomographic section of the investigated volume with the use of GeoTomCG software, which performs three-dimensional tomographic analysis with any source and receiver positions in a 3-D grid. The software allows for curved-ray calculations which have been observed to be more accurate in case of strong velocity contrasts. Curved ray tracing is performed with a revised form of ray bending, derived from the method of Um and Thurber (1987). Inversions are performed with the Simultaneous Iterative Reconstruction Technique (SIRT, Lytle et al., 1978; Peterson et al., 1985). The algorithm modifies the initial velocity model by repeated cycles of three steps: forward computation of model 
travel times, calculation of residuals and application of velocity corrections. We used the 2-D velocity field resulting from the surface seismic refraction tomography to construct the initial velocity model for cross-hole data inversion, using a squared cell size of $1 \mathrm{~m} \mathrm{x}$ $1 \mathrm{~m}$. All the cells of the final model having no ray coverage were rejected.

\subsection{Ultrasonic Pulse Velocity}

In order to lithologically constrain the seismic velocity range obtained from the field surveys, 7 blocks of granite, representing the degree of alteration of the natural material of the cliff, were collected from the site for laboratory testing of ultrasonic velocities. In addition, with the same aim, 20 granite outcrops in different alteration conditions were individuated in the sanctuary surroundings to be directly investigated on site with portable ultrasonic instrumentation. To perform the tests we used an ultrasonic pulse generator (Pundit) which provides emission (500V) and acquisition, with two pointsource (exponentially shaped) transducers having a nominal frequency of $54 \mathrm{kHz}$. We chose exponentially shaped probes because are expected to perform better than cylindrical transducers on rough or irregular surfaces, since the contact area with the sample is strongly reduced (head diameter $=6 \mathrm{~mm})$.

Calipers were used to accurately measure the width, length and thickness of the samples with volumes approximately varying from 250 to $25,000 \mathrm{~cm}^{3}$. Samples shape was selected to be almost equidimensional, with opposite parallel faces and smooth plane surfaces for ensuring the best contact between the transducers and the investigated rock sample (for each transducer the contact area is about $28 \mathrm{~mm}^{2}$ ). 
Measurements were conducted trying to follow as much as possible the requirements of the ASTM D2845-08 standard for laboratory determination of pulse velocities. All samples were selected in order to respect that the ratio of the investigated pulse travel distance $\mathrm{D}$ to the minimum lateral dimension $\mathrm{D}_{\min }$ not exceeded 5:

$$
\mathrm{D} \leq 5 \mathrm{D}_{\min }
$$

Moreover, to determine an accurate average propagation velocity, $\mathrm{D}$ shall be at least 10 times the average grain size $\mathrm{d}$ :

$\mathrm{D} \geq 10 \mathrm{~d}$

and $D_{\min }$ shall be at least 5 times the wavelength $\lambda$, so that the true dilational wave velocity is measured. The wavelength $\lambda$ corresponding to the dominant frequency of the pulse train is related to the natural resonance frequency of the transducers $f$ and to the pulse-propagation velocity $\mathrm{V}$ :

$$
\lambda=\frac{\mathrm{v}}{\mathrm{f}} .
$$

This shall be at least 3 times the average grain size, thus resulting in:

$$
D_{\min } \geq 5\left(\frac{V}{f}\right) \geq 15 d
$$

Granito di Alzo is a medium-grained granite having an average grain size variable from 2 to $4 \mathrm{~mm}$. Some samples exhibited a finer average grain, with a maximum crystal dimension of about $2 \mathrm{~mm}$. As a consequence, applying (2), we accepted the analyzed travel distances between $3.8 \mathrm{~cm}$ and $30.5 \mathrm{~cm}$. Considering the relatively low nominal frequency of the transducers $(54 \mathrm{kHz})$, compared to other cylindrical probes, and an approximate mean ultrasonic velocity of $3000 \mathrm{~m} / \mathrm{s}$, the expected wavelength $\lambda$ is $5.5 \mathrm{~cm}$. 
As a consequence, not all the samples fully satisfied (4), but it was at least ensured to have measurements on samples with $\mathrm{D}_{\min }>\lambda$.

Even if the majority of the samples appeared isotropic, some samples showed a slight degree of anisotropy due to layering. Measurements for these samples were therefore performed both in parallel and orthogonally to the observed layering.

The used sampling frequency was $2 \mathrm{MHz}$. For each sample the acquisitions were repeated 20 times in order to obtain several stable traces and to verify the repeatability of the measurements. The Power Spectral Density of the recorded signals was computed to check the dominant frequencies for the transmitted pulses. Manual picking of the first arrival time was performed on each recorded trace, in order to obtain the time of travel along the investigated distance. Determination of the velocity was straightforward as the geometry and the dimensions of samples were known. The mean velocity for each granite fragment was obtained as the mean of the 20 measurements carried out on the sample.

\subsection{Physical and mechanical characterization}

Additional samples (14) were collected for physical and mechanical characterization. Density, effective porosity and Point Load Strength measurements were carried out at the Rock\&Soil Physics Laboratory of the British Geological Survey (Keyworth, UK). Samples were cut in order to obtain sub-samples matching the ISRM suggested methods for rock characterization (ISRM, 1977; ISRM, 1981), resulting in irregular rock fragments. Fragments having a mass of at least $50 \mathrm{~g}$ and a minimum dimension greater than 10 times the largest grain size were selected, for a total number of 37 specimens to test (from 2 to 4 from each original granite sample). 
Tests were conducted following the "Suggested method for Porosity/Density Determination using Saturation and Buoyancy Techniques" of ISRM (1977). Essentially, each specimen was saturated by immersion in distilled water under a vacuum of $800 \mathrm{~Pa}$ for 2 hours. The mass of each sample was determined in saturated-submerged position $\left(\mathrm{M}_{\text {sat uw }}\right)$. After that, the specimens were removed from water and their surfaces dried using a moist cloth. In this condition, the saturated surface-dry mass was measured $\left(\mathrm{M}_{\mathrm{sat}} \mathrm{ds}\right)$. Samples were then dried in oven at $105^{\circ} \mathrm{C}$ for a night, whereupon the dry mass was determined $\left(\mathrm{M}_{\mathrm{od}}\right)$.

Densities $(\rho)$ and effective porosity $\left(\Phi_{\text {eff }}\right)$ were obtained following:

$$
\begin{aligned}
& \rho_{\text {dry }}=\frac{M_{\text {od }}}{M_{\text {sat ds }}-M_{\text {sat uw }}} \\
& \rho_{\text {saturated }}=\frac{M_{\text {sat ds }}}{M_{\text {sat ds }}-M_{\text {sat uw }}} \\
& \rho_{\text {particle }}=\frac{M_{\text {od }}}{M_{\text {od }}-M_{\text {sat uw }}} \\
& \phi_{\text {eff }}=100 \cdot \frac{M_{\text {sat ds }}-M_{\text {od }}}{M_{\text {sat ds }}-M_{\text {sat uw }}} .
\end{aligned}
$$

Point load tests were executed according to the Suggested Method for Determining Point Load Strength (ISRM, 1981; ISRM, 1985). The measurements can be conducted also on irregular rock fragments, if their size and shape satisfies the geometrical requirements described in the method. The load at which the sample fails is determined from the peak force applied by the steel points. The point load index Is is then defined as the ratio between the applied force at failure $(\mathrm{P})$ and the equivalent diameter of the core $\left(\mathrm{D}_{\mathrm{e}}\right)$ : 
$\mathrm{I}_{\mathrm{S}}=\frac{\mathrm{P}}{\mathrm{D}_{\mathrm{e}}^{2}}$

where:

$\mathrm{D}_{\mathrm{e}}^{2}=\frac{4 \mathrm{WD}}{\pi}$

with $\mathrm{D}$ the length of the sample in the loading section and $\mathrm{W}$ the width in the perpendicular direction.

The point load index depends on the diameter of the sample, so it must be corrected to the equivalent value representative for a $50 \mathrm{~mm}$ diameter core ( $\mathrm{I}_{\mathrm{S} 50)}$ :

$$
\mathrm{I}_{\mathrm{S} 50}=\left(\frac{\mathrm{D}_{\mathrm{e}}}{50}\right)^{0.45} \cdot \mathrm{I}_{\mathrm{S}}
$$

The diameter-corrected point load index (Is50) can be correlated with the uniaxial compressive strength $\left(\mathrm{C}_{0}\right)$ of the rock following:

$$
\mathrm{C}_{0}=22 \cdot \mathrm{I}_{\mathrm{S} 50} \cdot
$$

The point load test was performed on each sample used for density and porosity determination and, when feasible, also on the fragments of samples deriving from the test itself, in order to obtain from 3 to 15 measurements from each original sample. For each test the applied force at failure $(\mathrm{P})$ was recorded and corrected as described. Following ISRM suggestions, the minimum and maximum value of the measurements conducted on the same original sample where discarded. The remaining values were averaged to obtain the mean $\mathrm{C}_{0}$ value and the standard deviation for each original sample.

\section{RESULTS}

\subsection{Field seismic survey}


In Figure 5, the core logs and the RQD profiles of S1 and S5 are plotted for direct comparison with the $\mathrm{P}$ - and $\mathrm{SH}$-wave velocity profiles resulting from down-hole interpretation of the shots closest to the two boreholes (DH in Fig. 3) . Massive granite shows velocities up to $3500-4000 \mathrm{~m} / \mathrm{s}$ for P waves and $2100-2500 \mathrm{~m} / \mathrm{s}$ for $\mathrm{SH}$ waves in $\mathrm{S} 1$ at depths between 2 and $4 \mathrm{~m}$ and below $20 \mathrm{~m}$. Similar values are reached in S5 between $11 \mathrm{~m}$ and $14 \mathrm{~m}$ or below $18 \mathrm{~m}$. At depth of 8-11 $\mathrm{m}$ in S1 and 5-8 $\mathrm{m}$ in S5, velocity values decrease to a minimum of $1700 \mathrm{~m} / \mathrm{s}$ for $\mathrm{P}$ waves and $1000 \mathrm{~m} / \mathrm{s}$ for $\mathrm{SH}$ waves in presence of fractured horizons. In general terms, there is a good agreement between the RQD and the seismic velocity variations with depth. A decrease in the velocity values always corresponds to an increase in the fracturing conditions. It must be considered that the logs were executed several years (1981) before the geophysical tests of this study so that reactivation or further fracturing may not be evidenced in the same way in the two surveys.

The P- and SH-wave velocity sections obtained from cross-hole data inversion are reported in Figure 6 (respectively in a and b), together with their related ray coverage (c and d). The geometry of the survey was deeply limited by the impossibility of further lowering the in-hole source in $\mathrm{S} 2$, resulting in a reduced ray coverage in the central part of the section. Care must be taken when interpreting the seismic profile also considering the possible interference of tube waves due to the metallic hole casings. Nevertheless in both seismic profiles a top layer characterised by low velocity materials of about $2 \mathrm{~m}$ (top soil and highly altered/fractured granite, as also resulting from core loggings) is found. A clear reflector is noticed below this zone revealing an interface with an high-velocity heterogeneous formation. Intact granite velocity reaches about $2900-3100 \mathrm{~m} / \mathrm{s}$ for P waves 
and $1600-1800 \mathrm{~m} / \mathrm{s}$ for S waves. Two main low-velocity zones (about 2200-2400 m/s for $\mathrm{P}$ waves and $1200-1400 \mathrm{~m} / \mathrm{s}$ for $\mathrm{S}$ waves) are also found in both seismic profiles within the granitic mass. Apparent dip and dip direction of these zones (approximated dashed lines in Figure $6 a$ and $6 b$ ) fit the dip and direction of the K4 fracture system (50/75) whose traces are directly visible on the yard in front of the sanctuary and are locally revealed by the drillings. Their position on the front yard (Figure 3a) is also comparable to the one extrapolated from the seismic profiles.

In both images, the deeper low velocity zone is at the boundary of the investigated volume, in a zone with low density of rays, so with lower resolution. Nevertheless a further evidence of its existence could be that the majority of the seismic rays resulting from the deepest shot in S2 cluster above this zone, in a bend with the maximum ray coverage (up to 200 rays/node) while the usual trajectory in an homogeneous medium should be the nearly-straight one to directly reach the lowest geophones in S1. The second low velocity zone is instead located between the boreholes $\mathrm{S} 1$ and $\mathrm{S} 2$, at a distance of about $6 \mathrm{~m}$ from $\mathrm{S} 2$, progressively deepening towards $\mathrm{S} 1$.

These results show a good agreement with the down-hole profiles (representing the edges of the cross-hole sections) in term of depths and velocity variations, but downhole velocity contrasts appear to be more sharp and localized. This can be due to the different volumes investigated by the two methods. When down-hole test is interpreted, only data from a single shot position are available and the investigated model is essentially $1 \mathrm{D}$, thus resulting in a punctual seismic vertical profile that is very sensitive to local variations and shows clear strong contrast in the seismic velocities. In the cross-hole 
tomography all the shots from any in-hole or surface shot are considered together. The investigated volume is wider and the average velocity of each cell of the 2-D section is affected from all the rays crossing it. These considerations result in a less sharp seismic section, in which contrasts are more smoothed than in the down-hole profile, because of the complex medium, with massive/fractured zones and localized open fractures.

\subsection{Ultrasonic Pulse Velocity}

The velocity range obtained from the seismic surveys appeared to be quite low also within the detected massive granitic horizons; comparison with the ultrasonic velocity on rock samples was used for a direct check of the field measurements and for determining the physical state of the granite controlling this behaviour. The average ultrasonic velocity obtained on each sample is reported in Table 1. The average value computed on all the samples is $2728 \mathrm{~m} / \mathrm{s}$, with an associated standard deviation of $935 \mathrm{~m} / \mathrm{s}$, that suggests considerable variability among the tested samples (Figura 7a).

On the basis of the obtained values, we classified the investigated samples in three different classes: i) a first class with ultrasonic pulse velocities $V \leq V_{\text {mean }}$ - Standard Deviation $(\mathrm{V} \leq 1795 \mathrm{~m} / \mathrm{s})$; ii) an intermediate group with $\left(V_{\text {mean }}\right.$ - Standard Deviation $)<$ $V<\left(V_{\text {mean }}+\right.$ Standard Deviation $)$, that means $1793 \mathrm{~m} / \mathrm{s}<\mathrm{V}<3663 \mathrm{~m} / \mathrm{s}$, and iii) a third class with $V \geq V_{\text {mean }}+$ Standard Deviation $(\mathrm{V} \geq 3663 \mathrm{~m} / \mathrm{s})$.

Samples with velocity values in the range $\pm 50 \mathrm{~m} / \mathrm{s}$ from the boundary limits were assigned to the external classes in order to increase their population, and therefore their 
representativeness. The mean velocity values and standard deviations were then recalculated for each separated class and are reported in Figure 7b.

After this subdivision, we tried to link the observed velocity differences to physical characteristics of the samples and to the preliminary observations (weathering conditions and anisotropy) made before the measurement. The first class mainly encloses granite samples showing fractures or distributed alteration on the surface. Also measurements perpendicular to the weak layering of anisotropic samples, for which velocities recorded in parallel to the layering resulted in the intermediate group, fall in this class. The intermediate class includes samples in good shape, with only slight alteration surfaces or samples with finer grain size and measurements on specimens showing traces of layering and anisotropy both parallelly and perpendicularly to the measured direction. The third class includes intact samples in very good conditions, with coarser grain size and no alteration traces or visible anisotropies.

Six among the collected samples showed a low degree of anisotropy. On this samples measurements were performed both in parallel and perpendicularly to the planar layering, always resulting in a reduction in the mean velocities in the direction perpendicular to the anisotropy (Figure 8), varying from $-9 \%$ (sample 7 ) to $-45 \%$ (sample 8).

These results confirm that anisotropic velocity values, parallel and perpendicular to the foliation, reflect the internal structure of the samples related to the preferential alignment of the fabric. A perfect synthesis of the structural influence of the samples on the ultrasonic pulse velocity is shown in Figure 9. Fragments 1A and 1B were originally 
a single sample. During the transportation, a fracture occurred in the middle of the sample, along a planar weakness almost parallel to the layering. Measurements were conducted on the resulting bits, showing different velocity values depending on the orientation of the measurement with respect to the planar foliation. Then the two fragments were reassembled and a set of measurements was performed perpendicularly to the discontinuity, resulting in a mean velocity that is nearly half the velocity on the same direction detected on the individual fragments.

\subsection{Physical and mechanical characterization}

Resulting values of density and effective porosity are reported for each sample in Table 2, while Table 3 summarizes the values of Uniaxial Compressive Strength obtained from Point Load Test.

Even if direct ultrasonic velocity measurements on the samples are not available, an attempt to organize these samples on the basis of the same macroscopic classes individuated from the previous tests was made. Classes were assigned on the basis of macroscopic analysis, nearness of sampling point and similarities with the samples used for the ultrasonic tests. In Figure 10 the mean value of each parameter (density, effective porosity, uniaxial compressive strength) is reported for each of the resulting classes. It is clear from the data that there is a wide range of variation for the physical and mechanical properties among the samples and that a moderate to high variability is also revealed within each class. Density values, also for the third class, which groups massive unaltered samples, are quite low if compared with other studies on granites (Akyniemi et al., 2012; 
Cerillo et al., 2014; Vasconcelos et al., 2008;). Similarly, effective porosity values are very high, exceeding $1 \%$ in all the measurements, also for the intact samples. Uniaxial compressive strength presents some scatter even considering samples of the same class.

\section{DISCUSSION}

Results of the geophysical and laboratory characterization revealed an high variability in the physical properties of the studied granitic rock mass. In general, ultrasonic-pulse-velocity measurements performed both in laboratory and on the field, confirmed the velocity ranges resulting from the geophysical characterization of the site. The mean value of $\mathrm{Vp}$ for the intact granitic mass was around $2700 \mathrm{~m} / \mathrm{s}$, fully comparable with the mean ultrasonic pulse velocity of $2728 \mathrm{~m} / \mathrm{s}$. Only 11 ultrasonic measurements (on a total of 34) have values greater than $3100 \mathrm{~m} / \mathrm{s}$, the maximum value obtained for cross-hole seismic tomography. These highest ultrasonic velocities are of around 4300 $\mathrm{m} / \mathrm{s}$, confirming the locally higher values coming from down-hole interpretation. It is likely that the cross-hole seismic tomography results, that refer to a larger investigation volume, tend to smooth the strong velocity contrasts of the site. Using curved rays for the seismic inversion (that are expected to work better in presence of abrupt velocity changes) makes indeed very difficult to correctly trace their paths and visualize strong velocity contrasts in an almost intact granitic rock mass, cut by a few open cracks. At the site, in less than one meter we can find the transition between granite, air (open fracture) and granite again. The poor geometry of the survey, mainly imposed by the site morphology, does not help to overcome this problem. The internal contrast are however visible in the 
tomographic section, but results in a massive granitic formation with velocity values $\left(\mathrm{Vp}_{\text {mean }}=2700 \mathrm{~m} / \mathrm{s}\right)$ that are probably underestimated and fracture zones $\left(\mathrm{Vp}_{\text {mean }}=1900\right.$ $\mathrm{m} / \mathrm{s}$ ) which are correctly localized but show velocity values higher than the real ones.. Given the adequate correspondence in the resulting velocity range, a direct link between both seismic and ultrasonic velocities and both physical and mechanical properties of the in situ rock mass can be established. Correlations between density, porosity, compressive strength and ultrasonic pulse velocity (e.g. Vasconcelos et al., 2008) have been carried out to constrain the statistical trends and try to image the relevant physical parameters on site. Using the mean recorded ultrasonic pulse velocity of each class (V) we obtained the mean physical and mechanical parameters for each class as follows (modified from Vasconcelos et al., 2008):

$$
\begin{aligned}
\rho & =\frac{\mathrm{V}+22915}{10.043} \\
\Phi & =\left(\frac{\mathrm{V}}{3590}\right)^{-3.247} \\
\mathrm{C}_{0} & =0.0407 \mathrm{~V}-36.31
\end{aligned}
$$

where $\rho$ is dry density, $\phi$ is porosity and $\mathrm{C}_{0}$ is uniaxial compressive strength.

The results are summarized in Table 4. The linear correlation between dry density and ultrasonic pulse velocity seems to perfectly fit the data, with a maximum difference between the measured and the calculated density of $35 \mathrm{~kg} / \mathrm{m}^{3}$ for the intermediate class. Different results are found for porosity and uniaxial compressive strength. With respect to porosity, predicted values are largely overestimated for the first class, while values for the other two groups are lower than the real ones. Uniaxial compressive strength values 
are always overestimated, but, as mentioned before, they are very scattered so that the mean value of each class may not be completely representative. For example, looking at the third class, two samples (on a total of 4 measurements) exhibited values of $\mathrm{C}_{0}$ around $130 \mathrm{MPa}$,that perfectly fits with the calculated value of $126 \mathrm{MPa}$.

Given the good agreement between cross-hole tomography results and ultrasonic pulse velocity measurements, the same correlations were used for an approximate imaging of the physico-mechanical parameters within the rock mass by means of the cross-hole seismic section. Particularly, in Figure 11 we show the resulting section for dry density, which provided the most accurate predictions. The first meters of the section show the lowest density values in the highly altered and fractured granite. Massive granite shows density values above $2540 \mathrm{~kg} / \mathrm{m}^{3}$. On the other hand, the fractured zones exhibit a clear reduction in density. Geophysical data showed therefore potentiality to infer physical parameters' variability if properly calibrated at different scales. Moreover direct imaging of the variations of elastic moduli at the field scale, which can be used as direct input in numerical simulations, can be attempted by merging the seismic velocities and density sections.

Laboratory velocity measurements suggest that the strong alteration and the presence of microfractures at the mm-to-cm scale are likely to be the main reasons for the low velocity values measured. This structural control is largely amplified at the field scale, where the combined effect of microfractures and macroscopic open fractures results in a cross-hole seismic section with low apparent velocity values also for the more intact portions of the rock mass. This results is in agreement with the outcome of previous 
studies (Havenith et al., 2002; Heincke et al., 2006) on crystalline rock mass instabilities in which the ubiquitous presence of dry cracks and open fractures at a variety of scales is the most plausible explanation for the low velocities observed in the field results.

\section{CONCLUSIONS}

This work aimed to characterize the unstable rock mass of Madonna del Sasso by integrating field and laboratory geophysical approaches. Although the site setting made this study challenging, geophysical surveys provided new and valuable information for assessing the rock instability.

The seismic survey allowed investigation of the fracturing state of the granite cliff at depth, that helped to better understand the geometry of the unstable sector and to define a first velocity model for the site. The geophysical results agree with the outcomes of previous geomechanical analysis and evidences from borehole logs. Some quantitative discrepancy exist between cross-hole tomography results and down-hole measurements. Considering the complex morphological and geological context, cross-hole tomography contributed to spatially imaging the seismic velocity field of the site, enabling to locate the fracture zones and the relative velocity contrast. Down-hole tests conversely helped to define more punctual velocity values and to adjust the velocity values resulting from the tomography.

Measurements of the ultrasonic pulse velocity on samples collected at the site revealed a fast and simple method to lithologically interpret the field data, with a good 
agreement between the results at different scales. Moreover, since the ultrasonic pulse velocity is strongly dependent on the physical and mechanical parameters of the investigated medium, these direct measurements on granite samples allowed us to associate the different seismic velocity ranges to different macroscopic peculiarities (e.g. weathering conditions and presence of anisotropy) of the granites.

All the results confirm the presence and persistence within the rock mass of deep and pervasive fracture zones which isolate the prone-to-fall frontal portions of the cliff. Moreover, the quite low seismic velocities in the whole unstable sector probably suggest the widespread presence of dry cracks and minor fractures at different scales. Therefore considering the geophysical results and the growing people's awareness of the risk related to the site, further monitoring is required with unconventional methodologies. With this aim, early warning systems based on microseismic monitoring, for which this study supplies the basis of the seismic characterization of the site, could be potentially helpful in detecting incipient fracturing and forecasting the macroscopic failure.

\section{ACKNOWLEDGEMENTS}

Geophysical tests of this study have been funded within the Progetto d'Ateneo 2012 - SAFER of Università degli Studi di Torino: "Detecting Slow Deformation Signals Preceding Dynamic Failure: A New Strategy For The Mitigation Of Natural Hazards". Authors are indebted with Politecnico di Torino for the use of seismic instrumentation and interpretation software.

\section{REFERENCES}


Akinyemi, O. D., Alabi, A. A., Ojo, A. I., Adewusi, O. E., 2012. Characterization of Density and Porosity of Rocks Samples from Ogun State of Nigeria. Journal of African Earth Science Research, 1, 2, 98-105.

ASTM D2845-08, Standard Test Method for Laboratory Determination of Pulse Velocities and Ultrasonic Elastic Constants of Rock, ASTM, International (American Society for Testing and Materials), West Conshohocken, Pennsylvania, USA, 2008.

Benson, P. M., Thompson, B. D., Meredith, P. G., Vinciguerra, S., Young, R. P., 2007. Imaging slow failure in triaxially deformed Etna basalt using 3D acoustic-emission location and X-ray computed tomography, Geophys. Res. Lett., 34, L03303. doi:10.1029/ 2006GL028721.

Boriani, A., Caironi, V., Giobbi Origoni, E., Vannucci, R., 1992. The Permian intrusive rocks of Serie dei Laghi (Western Southern Alps). Acta Vulcanol., 2, 73-86.

Bogoslovsky, V. A., Ogilvy A. A., 1977. Geophysical methods for the investigation of landslides. Geophysics, 42, 3, 562-571.

Bregman, N. D., Bailey, R. C., Chapman, C. H., 1989. Crosshole seismic tomography. Geophysics, 54, 200-215.

Bruno, F., Marillier, F., 2000. Test of high-resolution seismic reflection and other geophysical techniques on the Boup landslide in the Swiss Alps. Surv. Geophys., $21,333-348$.

Calnan, C., Schuster, G. T., 1989. Reflection and transmission cross-well tomography. 59th Ann. Internat. Mtg., Soc. Expl. Geophys., Expanded Abstracts, 908-911. 
Cerrillo, C., Jiménez, A., Rufo, M., Paniagua, J., Pachón, F. T., 2014. New contributions to granite characterization by ultrasonic testing. Ultrasonics, 54, 1, 156-167.

Chaki, S., Takarli, M., Agbodjan, W.P., 2008. Influence of thermal damage on physical properties of a granite rock: Porosity, permeability and ultrasonic wave evolutions. Construction and Building Materials, 22, 7, 1456-1461.

Chen, S. T., Zimmerman, L. J. and Tugnait, J. K., 1990. Subsurface imaging using reversed vertical seismic profiling and crosshole tomographic methods. Geophysics, $55,1478-1487$.

Ciccotti M. and Mulargia F., 2004. Differences between static and dynamic elastic moduli of a typical seismogenic rock. Geophysical Journal International, 157, 474-477. doi: 10.1111/j.1365-246X.2004.02213.x.

Giobbi Origoni, E., Bocchio, E., Boriani, A., Carmine, R. and De Capitani, L., 1988. LateHercynian mafic and intermediate intrusives of Serie dei Laghi (N-Italy). Rend. Soc. It. Mineral. Petrol., 43, 395-410.

Hadley, K., 1976. Comparison of calculated and observed crack densities and seismic velocities in Westerly granite. J. Geophys. Res., 81, 3484-3493.

Havenith, H. B., Jongmans, D., Faccioli, E., Abdrakhmatov, K., Bard, P. Y., 2002. Site effect analysis around the seismically iduced Ananevo rockslide, Kyrgyzstan. Bull. Seis. Soc. Am., 92, 3190-3209. 
Heincke, B., Maurer, H., Green, A. G., Willenberg, H., Spillmann, T. and Burlini, L., 2006. Characterizing an unstable mountain slope using shallow 2D and 3D seismic tomography, Geophysics, 71, 6, B241-B256. doi: 10.1190/1.2338823.

ISRM, 1977. ISRM Suggested method for porosity/density determination using saturation and buoyancy techniques. In: Brown, E. (Ed.). Rock Characterization Testing \& Monitoring. 84- 86.

ISRM, 1981. Rock Characterization, Testing and Monitoring: ISRM Suggested Methods. Editor: Brown, E. T., Pergamon press, 211 pp.

ISRM, 1985. Suggested Methods for Determining Point Load Strength.

Jongmans, D., Garambois, S., 2007. Geophysical investigation of landslides: a review. Bulletin de la Société Géologique de France, 178, 2, 101-112.

Jongmans, D., Hemroulle, P., Demanet, D., Renardy, F., Vanbrabant, Y., 2000. Application of 2D electrical and seismic tomography techniques for investigating landslides. Eur. J. Environ Eng Geophys, 8, 75-89.

Lancellotta, R., Gigli, P., Pepe, C., 1991. Relazione tecnica riguardante la caratterizzazione geologico-strutturale dell'ammasso roccioso e le condizioni di stabilità della rupe, commissionata dal Ministero dei Lavori Pubblici Provveditorato alle Opere Pubbliche per il Piemonte e la Valle d'Aosta. Private communication.

Lines, L. R., LaFehr, E. D., 1989. Tomographic modeling of a cross-borehole data set. Geophysics, 54, 1249-1257. 
Lytle, R. J, Dines, K. A., Laine, E. F., Lager, D. L., 1978. Electromagnetic Cross-Borehole Survey of a Site Proposed for an Urban Transit Station. UCRL-52484, Lawrence Livermore Laboratory, University of California, 19 pp.

Maurer, H., Spillmann, T., Heincke, B., Hauck, C., Loew, S., Springman, S.M., Green, A.G., 2010. Geophysical characterization of slope instabilities. First Break, 28, 8, Special topic: Near Surface Geoscience, 53-61.

Mauritsch, J. H., Seiberl, W., Arndt, R., Römer, A., Schneiderbauer, K., Sendlhofer, G. P., 2000. Geophysical investigations of large landslides in the Carnic Region of southern Austria. Eng. Geol., 56, 373-388.

Mavko, G., Nur, A., 1975. Melt squirt in asthenosphere. J. Geophys. Res., 80, 1444-1448.

McMechan, G. A., Harris, J. M., Anderson, L. M., 1987. Cross-hole tomography for strongly variable media with applications to scale model data. Bull. Seis. Soc. Am., 77, 1945-1960.

Méric, O., Garambois, S., Cadet, H., Malet, J-P., Guéguen, P., Jongmans, D., 2007. Seismic noise based methods for soil landslide characterization. Bulletin de la Société Géologique de France, 178, 2, 137-148.

O'Connel, R. J., Budiansky, B., 1976. Seismic velocities in dry and saturated cracked solids. J. Geophys. Res., 79, 5413-5426.

Peterson, J. E., Paulson, B. N. P., McEvilly, T. V., 1985. Applications of Algebraic Reconstruction Techniques to Crosshole Seismic Data. Geophysics, 50, 1566-1580.

Regione Piemonte, 1993. La rete di controllo della rupe di Madonna del Sasso, sintesi dei risultati dei primi 18 mesi di misure. Assessorato Difesa del Suolo e Governo 
Risorse Idriche. Settore per la prevenzione del rischio geologico, meteorologico e sismico. Servizio interventi progettuali geologico-tecnici, pronto intervento e verifica grandi opere infrastrutturali. $52 \mathrm{pp}$.

Schubnel, A., Gueguen, Y., 2003. Dispersion and anisotropy of elastic waves in cracked rocks. J. Geophys. Res., 108 (B2), 2101. doi:10.1029/2002JB001824.

Stanchits, S., Vinciguerra, S., Dresen, G., 2006. Ultrasonic Velocities, Acoustic Emission Characteristics and Crack Damage of Basalt and Granite. Pure Appl. Geophys. 163, 5-6, 975-994. doi: 10.1007/s00024-006-0059-5.

Thomsen, L., 1985. Biot-consistent elastic moduli of porous rocks: low freqeuncy limit. Geophysics, 50, 2797-2807.

Um, J., Thurber, C. H., 1987. A fast algorithm for two-point seismic ray tracing. Bull. Seismol. Soc. Am. 77: 972-986.

Vasconcelos, G., Lourenço, P. B., Alves, C. A., Pamplona, J., 2008. Ultrasonic evaluation of the physical and mechanical properties of granites. Ultrasonics, 48, 5, 453-466. doi: 10.1016/j.ultras.2008.03.008.

Vinciguerra, S., Trovato, C., Meredith, P. G., Benson P. M., 2005. Relating seismic velocities, thermal cracking and permeability in Mt. Etna and Iceland basalts. Int. J. Rock Mech. Min. Sci., 42, 900-910.

Zamora, M., Sartoris, G., Chelini, W., 1994. Laboratory measurements of ultrasonic wave velocities in rocks from the Campi Flegrei volcanic system and their relation to other field data. Journal of Geophysical Research, 99 (B7), 13553-13562. 


\section{TABLES}

Table 1. Ultrasonic pulse velocity test: $\mathrm{D}(\mathrm{m})$ distance between transmitter and receiver; $\mathrm{V}_{\text {mean }}$ average velocity obtained from 20 measurements repeated on the same path; $\mathrm{V}_{\max }$ and $V_{\text {min }}$ maximum and minimum velocity between the 20 recordings. Standard Deviation (St Dev) of the measurements and some macroscopic features of the samples are also reported.

\begin{tabular}{|c|c|c|c|c|c|c|}
\hline $\begin{array}{c}\text { Sample } \\
n .\end{array}$ & $\begin{array}{c}D \\
{[m]}\end{array}$ & $V_{\text {mean }}[\mathrm{m} / \mathrm{s}]$ & $V_{\max }[\mathrm{m} / \mathrm{s}]$ & $V \min [m / s]$ & $\begin{array}{l}\text { St Dev } \\
{[\mathrm{m} / \mathrm{s}]}\end{array}$ & Description \\
\hline $1 A / /$ & 0.141 & 4222 & 4538 & 4046 & 180 & // layering \\
\hline $1 A \perp$ & 0.077 & 3285 & 3459 & 3179 & 99 & $\perp$ layering \\
\hline $1 B / /$ & 0.105 & 3875 & 4321 & 3678 & 185 & // layering \\
\hline $1 B \perp$ & 0.085 & 3443 & 3584 & 3290 & 105 & $\perp$ layering \\
\hline $1 A+1 B$ & 0.170 & 1812 & 1936 & 1564 & 106 & fracture between $1 A$ and $1 B$ \\
\hline 2 & 0.062 & 3373 & 3830 & 3133 & 213 & isotropic \\
\hline 3 & 0.130 & 3424 & 3587 & 3314 & 84 & isotropic \\
\hline $4 / /$ & 0.094 & 2703 & 2938 & 2552 & 112 & // layering \\
\hline $4 / /$ & 0.190 & 2733 & 2771 & 2702 & 23 & // layering \\
\hline 41 & 0.041 & 2366 & 2801 & 2186 & 161 & $\perp$ layering \\
\hline $5 a$ & 0.067 & 1439 & 1550 & 1354 & 54 & isotropic, really altered \\
\hline $5 b$ & 0.084 & 1425 & 1499 & 1365 & 43 & isotropic, really altered \\
\hline $6 / /$ & 0.082 & 1954 & 2013 & 1895 & 39 & // layering \\
\hline $6 \perp$ & 0.061 & 1231 & 1305 & 1159 & 46 & $\perp$ layering \\
\hline $7 / /$ & 0.305 & 4027 & 4133 & 3911 & 57 & // layering \\
\hline 71 & 0.098 & 3673 & 3871 & 3452 & 151 & $\perp$ layering \\
\hline $8 / /$ & 0.185 & 2892 & 2967 & 2820 & 41 & // layering \\
\hline $8 \perp$ & 0.096 & 1587 & 1859 & 1447 & 108 & $\perp$ layering \\
\hline 9 & 0.170 & 3192 & 3291 & 3081 & 59 & isotropic \\
\hline 10 & 0.127 & 1803 & 2155 & 1585 & 140 & $\perp$ layering \\
\hline 11 & 0.141 & 4261 & 4518 & 4113 & 96 & isotropic \\
\hline 12 & 0.106 & 2391 & 2503 & 2301 & 59 & isotropic, finer grain size \\
\hline 13 & 0.038 & 1092 & 1161 & 1047 & 29 & isotropic, really altered \\
\hline 14 & 0.068 & 1166 & 1200 & 1129 & 14 & isotropic, really altered \\
\hline 15 & 0.124 & 3056 & 3253 & 2862 & 107 & isotropic, altered \\
\hline 16 & 0.081 & 4237 & 4472 & 3942 & 140 & isotropic \\
\hline 17 & 0.065 & 2170 & 2303 & 2043 & 60 & isotropic, weak alteration \\
\hline 18 & 0.107 & 2550 & 2618 & 2470 & 44 & isotropic, weak alteration \\
\hline 19 & 0.150 & 2648 & 2692 & 2598 & 25 & isotropic, weak alteration \\
\hline 20 & 0.125 & 2624 & 2734 & 2564 & 49 & isotropic, weak alteration \\
\hline 21 & 0.091 & 2499 & 2628 & 2412 & 65 & isotropic, weak alteration \\
\hline 22 & 0.066 & 2877 & 3266 & 2691 & 156 & isotropic \\
\hline 23 & 0.128 & 3009 & 3070 & 2942 & 33 & isotropic \\
\hline 24 & 0.230 & 3714 & 3852 & 3552 & 77 & isotropic \\
\hline
\end{tabular}


Table 2. Density and effective porosity results.

\begin{tabular}{|c|c|c|c|c|c|c|c|c|}
\hline \multicolumn{2}{|c|}{ Lab. No. } & \multicolumn{3}{|c|}{ Measured weigth (g) } & \multicolumn{3}{|c|}{ Density $\left(\mathrm{kg} / \mathrm{m}^{3}\right)$} & \multirow{2}{*}{$\begin{array}{c}\text { Effective } \\
\text { porosity [\%] }\end{array}$} \\
\hline Sample & N/A & Oven Dry & Saturated & $\begin{array}{c}\text { Saturated } \\
\text { under water }\end{array}$ & Dry & Saturated & Particle & \\
\hline GR1 & $\mathbf{A}$ & 126.97 & 130.85 & 78.46 & 2424 & 2498 & 2617 & 7.42 \\
\hline GR1 & B & 324.89 & 333.65 & 202.18 & 2471 & 2538 & 2648 & 6.66 \\
\hline GR1 & C & 262.76 & 270.7 & 163.35 & 2448 & 2522 & 2643 & 7.4 \\
\hline GR2 & $\overline{\mathbf{A}}$ & 68.9 & 71.51 & 42.19 & 2350 & 2439 & 2580 & 8.89 \\
\hline GR2 & B & 48.88 & 50.74 & 29.34 & 2284 & 2371 & 2502 & 8.68 \\
\hline GR3 & $\overline{\mathbf{A}}$ & 261.64 & 266.94 & 162.51 & 2505 & 2556 & 2639 & 5.07 \\
\hline GR3 & B & 216.88 & 220.43 & 134.52 & 2525 & 2566 & 2633 & 4.12 \\
\hline GR4 & $\mathbf{A}$ & 222.46 & 225.51 & 137.66 & 2532 & 2567 & 2623 & 3.47 \\
\hline GR4 & B & 176.36 & 178.78 & 109.49 & 2545 & 2580 & 2637 & 3.49 \\
\hline GR5 & $\mathbf{A}$ & 220.8 & 226.35 & 136.93 & 2469 & 2531 & 2633 & 6.2 \\
\hline GR5 & B & 322.59 & 330.31 & 199.98 & 2475 & 2534 & 2631 & 5.92 \\
\hline GR5 & C & 272.28 & 279.43 & 169.09 & 2468 & 2532 & 2639 & 6.48 \\
\hline GR5 & D & 94.25 & 96.61 & 57.39 & 2403 & 2463 & 2557 & 6 \\
\hline GR6 & $\mathbf{A}$ & 153.86 & 156.63 & 94.42 & 2473 & 2518 & 2588 & 4.45 \\
\hline GR6 & B & 246.96 & 251.43 & 153.18 & 2514 & 2559 & 2633 & 4.56 \\
\hline GR7 & $\overline{\mathbf{A}}$ & 204.99 & 208.27 & 127.04 & 2524 & 2564 & 2630 & 4.03 \\
\hline GR7 & B & 97.29 & 98.79 & 59.9 & 2502 & 2540 & 2602 & 3.85 \\
\hline GR7 & C & 207.18 & 210.58 & 128.56 & 2526 & 2567 & 2635 & 4.15 \\
\hline GR8 & $\overline{\mathbf{A}}$ & 292.43 & 296.8 & 181.38 & 2534 & 2571 & 2633 & 3.78 \\
\hline GR8 & B & 151.21 & 153.24 & 93.71 & 2540 & 2574 & 2630 & 3.41 \\
\hline GR9 & $\overline{\mathbf{A}}$ & 139.06 & 139.96 & 85.73 & 2564 & 2581 & 2608 & 1.66 \\
\hline GR9 & B & 143.52 & 144.61 & 87.98 & 2534 & 2554 & 2584 & 1.93 \\
\hline GR10 & $\overline{\mathbf{A}}$ & 262.2 & 264.79 & 162.19 & 2556 & 2581 & 2622 & 2.53 \\
\hline GR10 & B & 399.58 & 404.54 & 247.28 & 2541 & 2572 & 2624 & 3.16 \\
\hline GR11 & $\overline{\mathbf{A}}$ & 172.98 & 175.77 & 107.01 & 2516 & 2556 & 2622 & 4.06 \\
\hline GR11 & B & 242.05 & 246.99 & 150.39 & 2506 & 2557 & 2641 & 5.11 \\
\hline GR11 & C & 310.66 & 316.65 & 192.01 & 2492 & 2541 & 2618 & 4.81 \\
\hline GR12 & $\mathbf{A}$ & 149.81 & 150.78 & 92.66 & 2578 & 2594 & 2621 & 1.67 \\
\hline GR12 & B & 137.44 & 138.49 & 84.23 & 2533 & 2552 & 2583 & 1.92 \\
\hline GR13 & $\mathbf{A}$ & 357.64 & 359.55 & 221.36 & 2588 & 2602 & 2624 & 1.38 \\
\hline GR13 & B & 252.45 & 253.8 & 156.47 & 2594 & 2608 & 2630 & 1.38 \\
\hline GR13 & C & 155.83 & 156.86 & 96.33 & 2574 & 2591 & 2619 & 1.7 \\
\hline GR13 & D & 279.05 & 280.76 & 172.53 & 2578 & 2594 & 2620 & 1.58 \\
\hline GR14 & $\mathbf{A}$ & 288.16 & 290.32 & 179.32 & 2596 & 2615 & 2648 & 1.94 \\
\hline GR14 & B & 283.27 & 285.8 & 175.56 & 2570 & 2593 & 2630 & 2.3 \\
\hline GR14 & C & 194.44 & 195.88 & 120.15 & 2568 & 2587 & 2617 & 1.91 \\
\hline GR14 & D & 95.5 & 96.31 & 58.96 & 2557 & 2579 & 2614 & 2.16 \\
\hline
\end{tabular}


Table 3. Point Load Test results.

\begin{tabular}{|c|c|c|c|c|}
\hline Sample & $\begin{array}{c}\text { Mean } \\
\mathbf{I}_{\text {S50 }}\end{array}$ & $\begin{array}{c}\text { St Dev } \\
\mathbf{I}_{\text {S50 }}\end{array}$ & $\begin{array}{c}\text { Mean } \mathbf{C}_{\mathbf{0}} \\
\text { (MPa) }\end{array}$ & $\begin{array}{c}\text { St Dev } \mathbf{C}_{\mathbf{0}} \\
\text { (MPa) }\end{array}$ \\
\hline GR1 & 0.49 & 0.27 & 10.8 & 6.0 \\
\hline GR2 & 0.55 & 0.32 & 12.0 & 7.0 \\
\hline GR3 & 1.62 & 0.27 & 35.7 & 12.8 \\
\hline GR4 & 2.51 & 0.58 & 55.1 & 3.5 \\
\hline GR5 & 0.37 & 0.16 & 8.2 & 9.7 \\
\hline GR6 & 1.12 & 0.44 & 24.6 & 5.5 \\
\hline GR7 & 0.44 & 0.25 & 9.7 & 6.3 \\
\hline GR9 & 1.78 & 0.38 & 39.2 & 17.4 \\
\hline GR10 & 6.04 & 2.85 & 132.9 & 5.0 \\
\hline GR11 & 0.64 & 0.23 & 55.0 & 24.3 \\
\hline GR12 & 3.15 & 1.10 & 14.2 & 21.7 \\
\hline GR13 & 6.07 & 0.99 & 69.3 & 17.4 \\
\hline GR14 & 4.04 & 0.79 & 133.6 & 89.0 \\
\hline
\end{tabular}

Table 4. Correlation between the ultrasonic pulse velocity (V) and the physical and mechanical parameters measured in laboratory or calculated from the correlations modified from Vasconcelos et al. (2008).

\begin{tabular}{|c|c|c|c|c|c|c|c|}
\hline \multirow{2}{*}{ Class } & \multirow{2}{*}{$\mathbf{V}(\mathbf{m} / \mathbf{s})$} & \multicolumn{2}{|c|}{$\rho_{\text {dry }}\left(\mathbf{k g} / \mathbf{m}^{\mathbf{3}}\right)$} & \multicolumn{2}{c|}{$\Phi_{\text {eff }}(\boldsymbol{\%})$} & \multicolumn{2}{c|}{$\mathbf{C}_{\mathbf{0}}(\mathbf{M P a})$} \\
\cline { 3 - 8 } & & measured & calculated & measured & calculated & measured & calculated \\
\hline $\mathbf{1}$ & 1444 & 2430.9 & 2425 & 7.1 & 19.2 & 13.8 & 22.4 \\
\hline $\mathbf{2}$ & 2799 & 2525.0 & 2560 & 3.9 & 2.24 & 34.8 & 77.6 \\
\hline $\mathbf{3}$ & 4001 & 2569.2 & 2680 & 1.8 & 0.7 & 106.2 & 126.53 \\
\hline
\end{tabular}




\section{FIGURES}

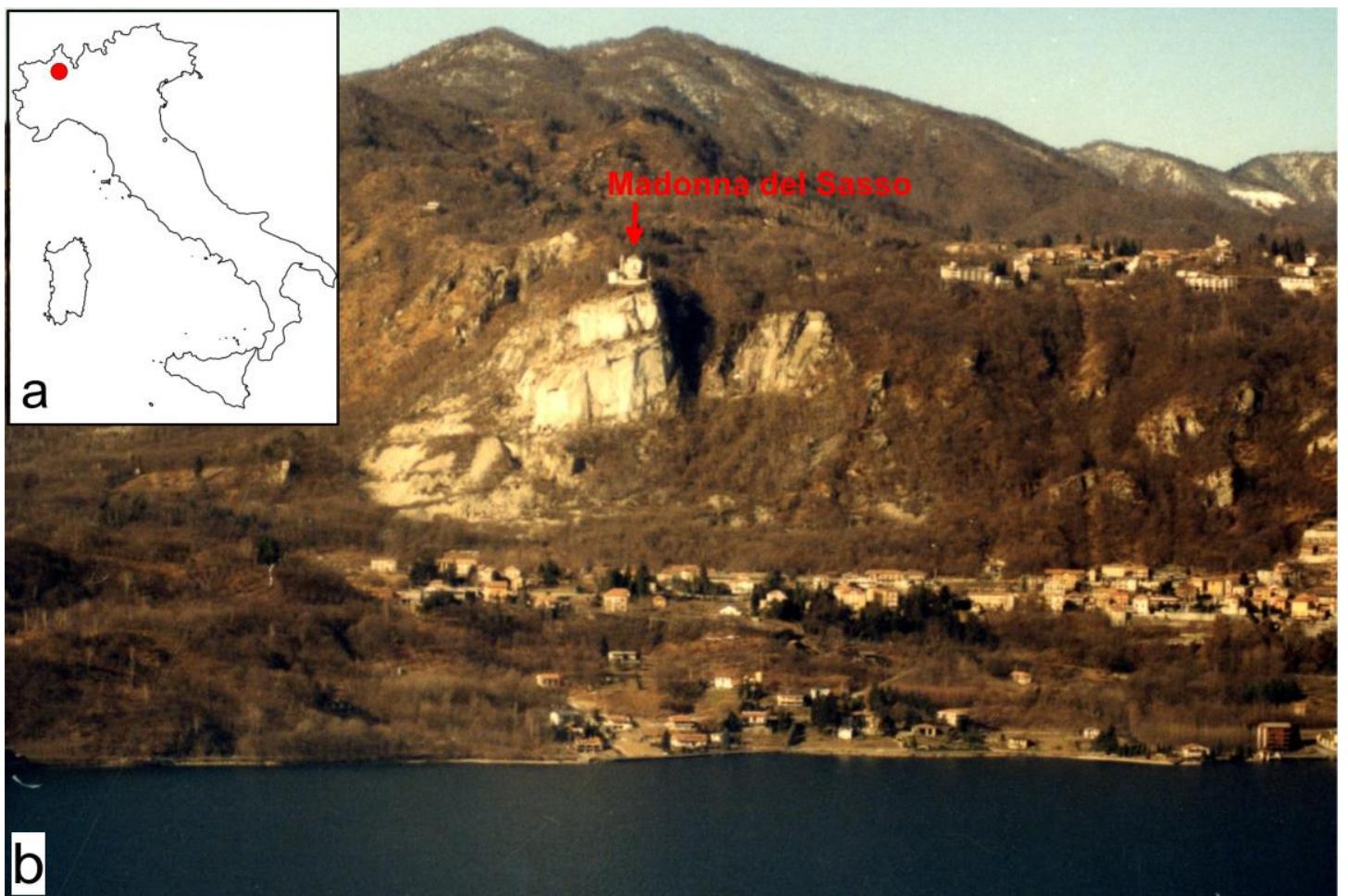

Figure 1. Geographical location (a) and eastern aerial view (b) of the cliff of Madonna del Sasso from the Orta Lake. 

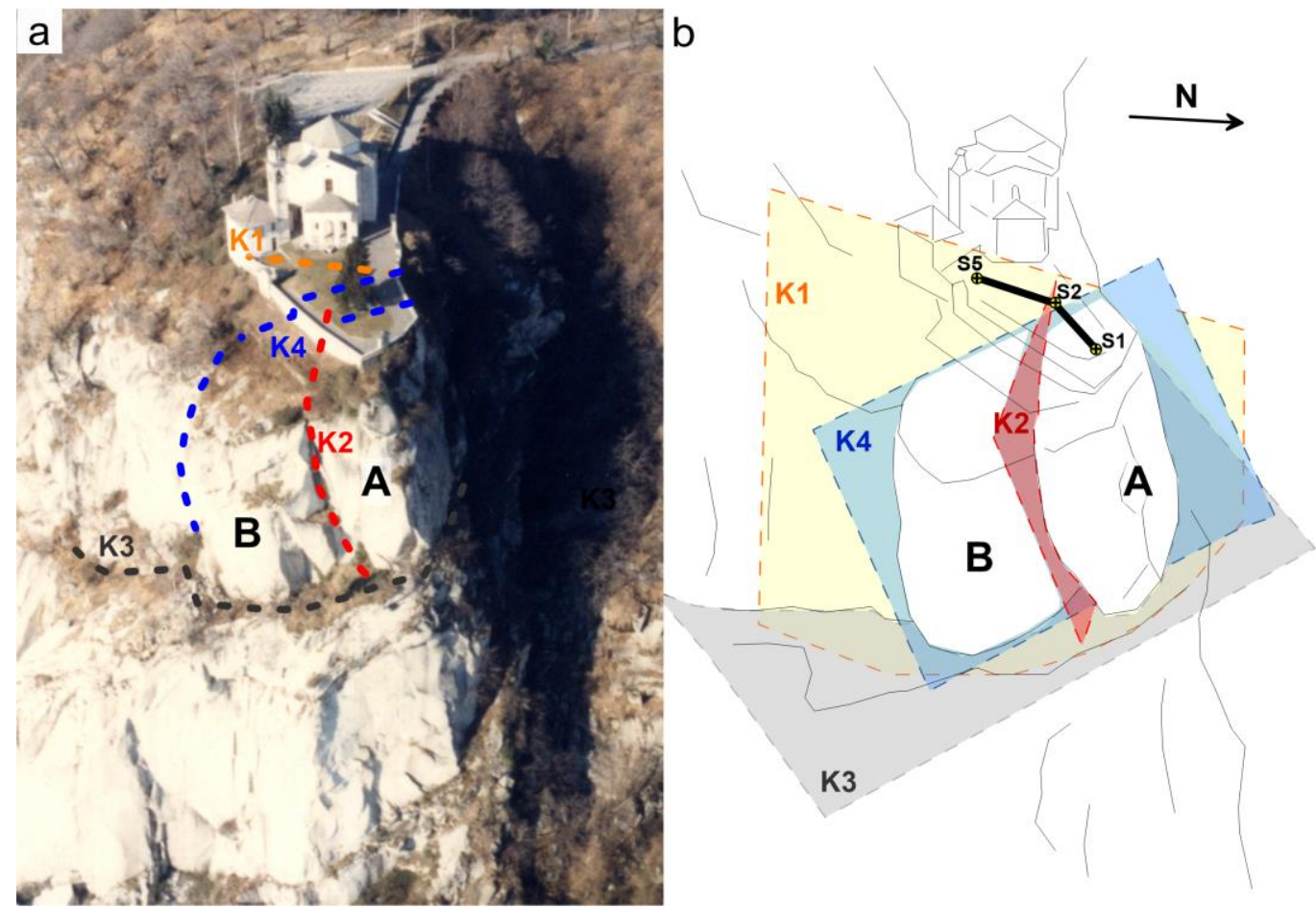

Figure 2. Aerial view (a) and schematic representation (b) of the major fracture traces and discontinuity planes isolating the frontal portions of the site (sector A: $12,000 \mathrm{~m}^{3}$ and sector B: 7,500 $\mathrm{m}^{3}$ ). The black bold line (in b) refers to the seismic cross-hole survey between the inclinometric boreholes ( 1 1, S2 and S5). 


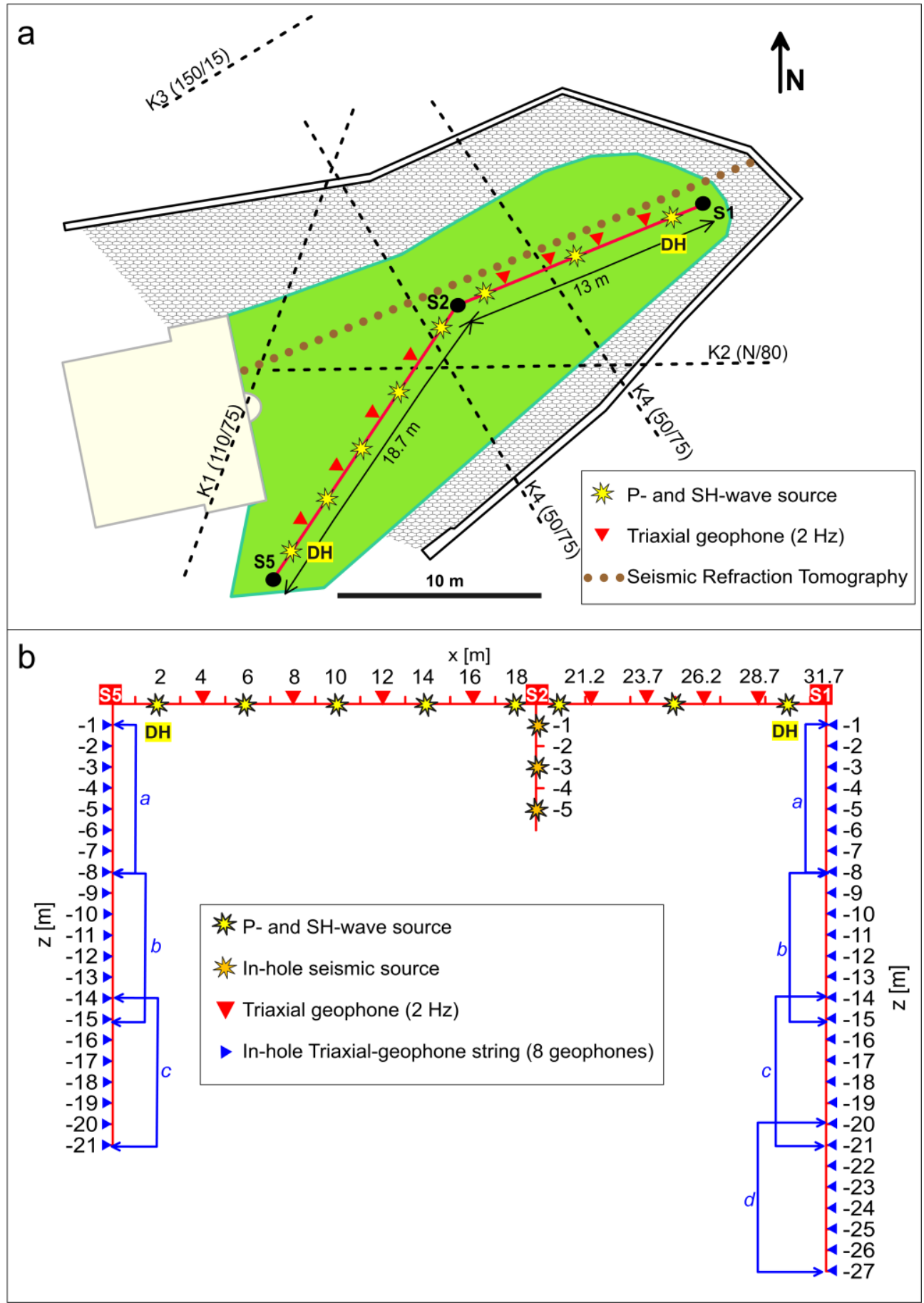

Figure 3. Cross-hole seismic tomography configuration: planar view (a) and section (b). 

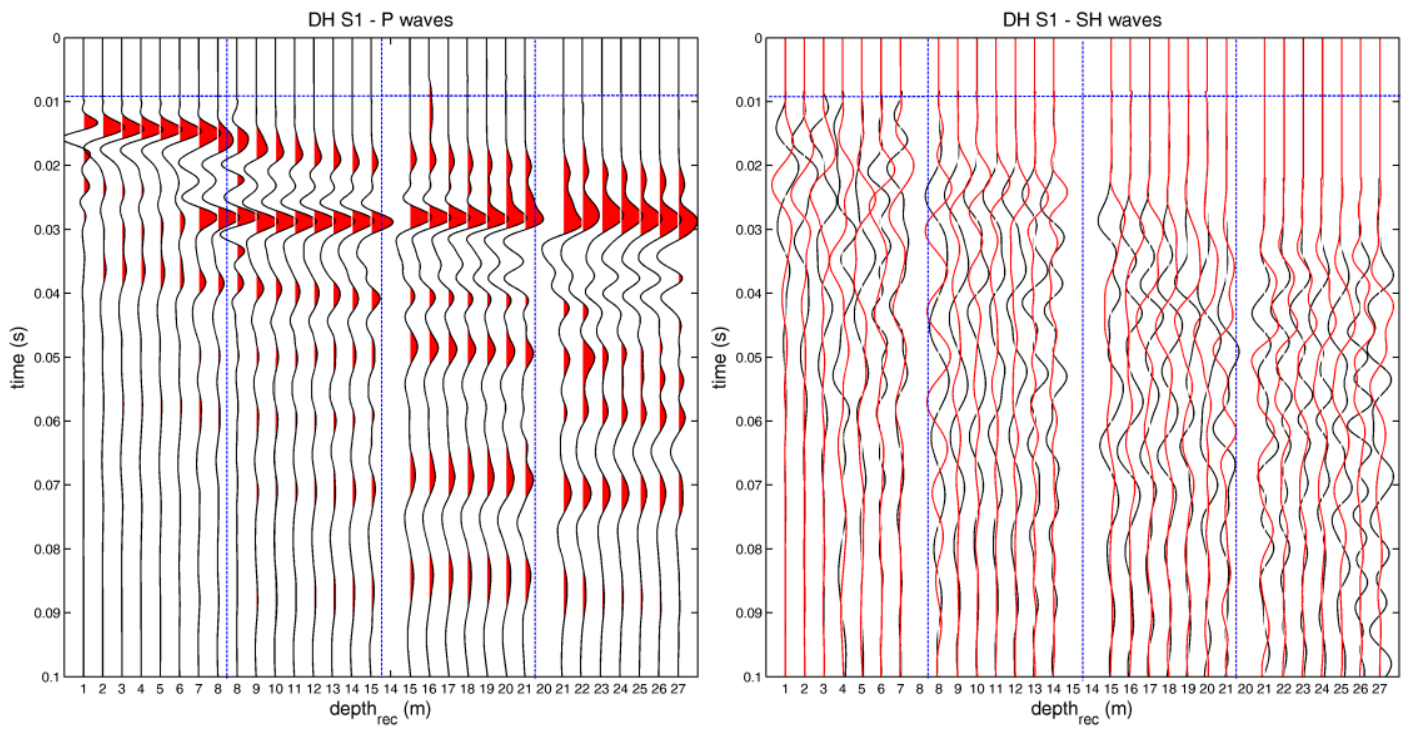

Figure 4. Example of reconstructed seismograms of P-waves (a) and $\mathrm{SH}$-waves (b) for the surface shot closest to $\mathrm{S} 1$ sounding (distance $=1.5 \mathrm{~m}$ ). Vertical dashed lines separate consecutive positions of the in-hole geophone string. The dashed horizontal line refers to the time delay $(96 \mathrm{~ms})$ used for the acquisition. These data were also used for down-hole interpretation. 


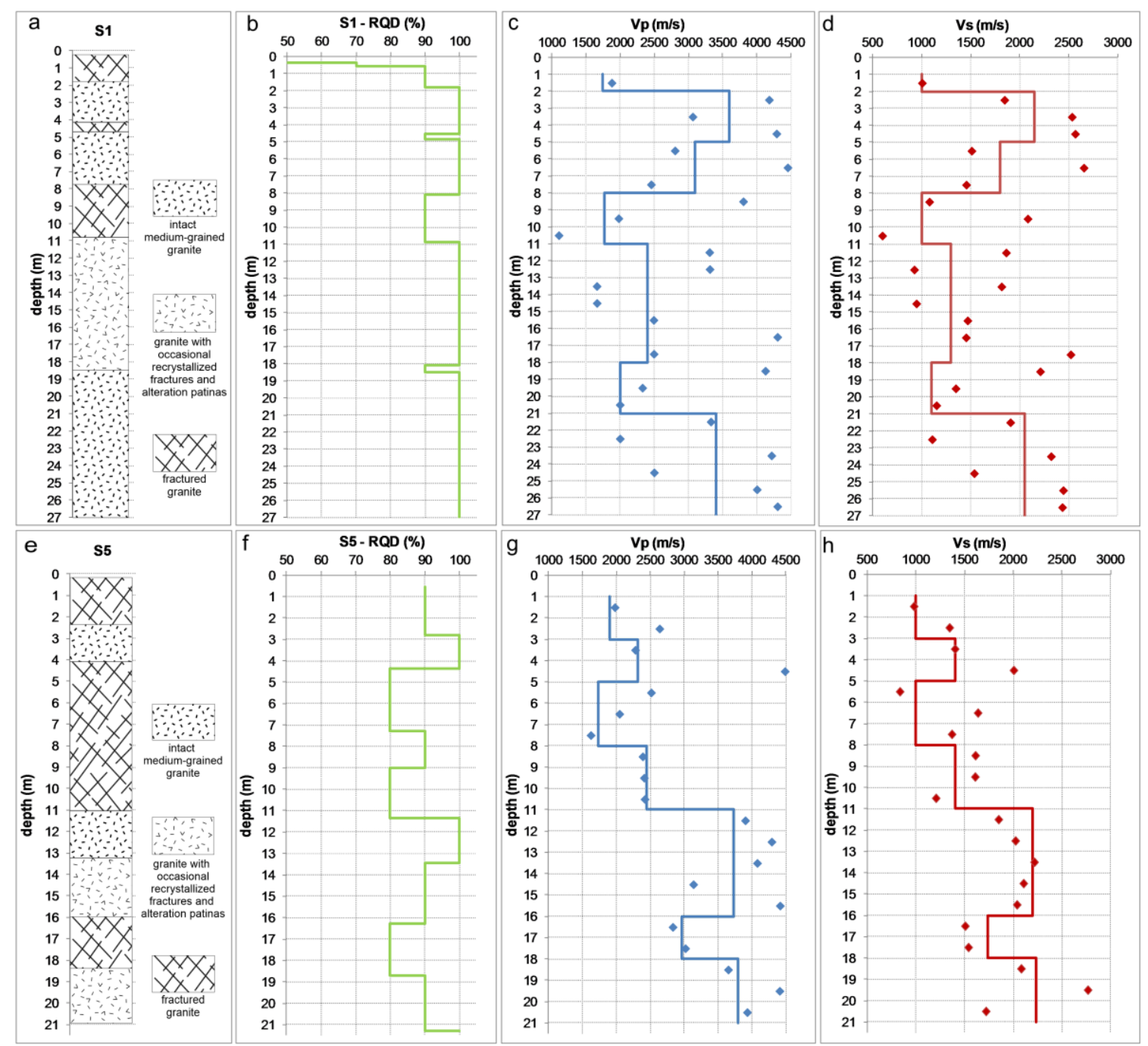

Figure 5. Core logs for S1 (a) and S5 (e) compared with RQD values (b and f), P-wave velocity profiles (c and $\mathrm{g}$ ) and $\mathrm{S}$-wave velocity profiles ( $\mathrm{d}$ and $\mathrm{h}$ ) both in interval velocity (continuous lines) and true interval (dots) interpretations. 


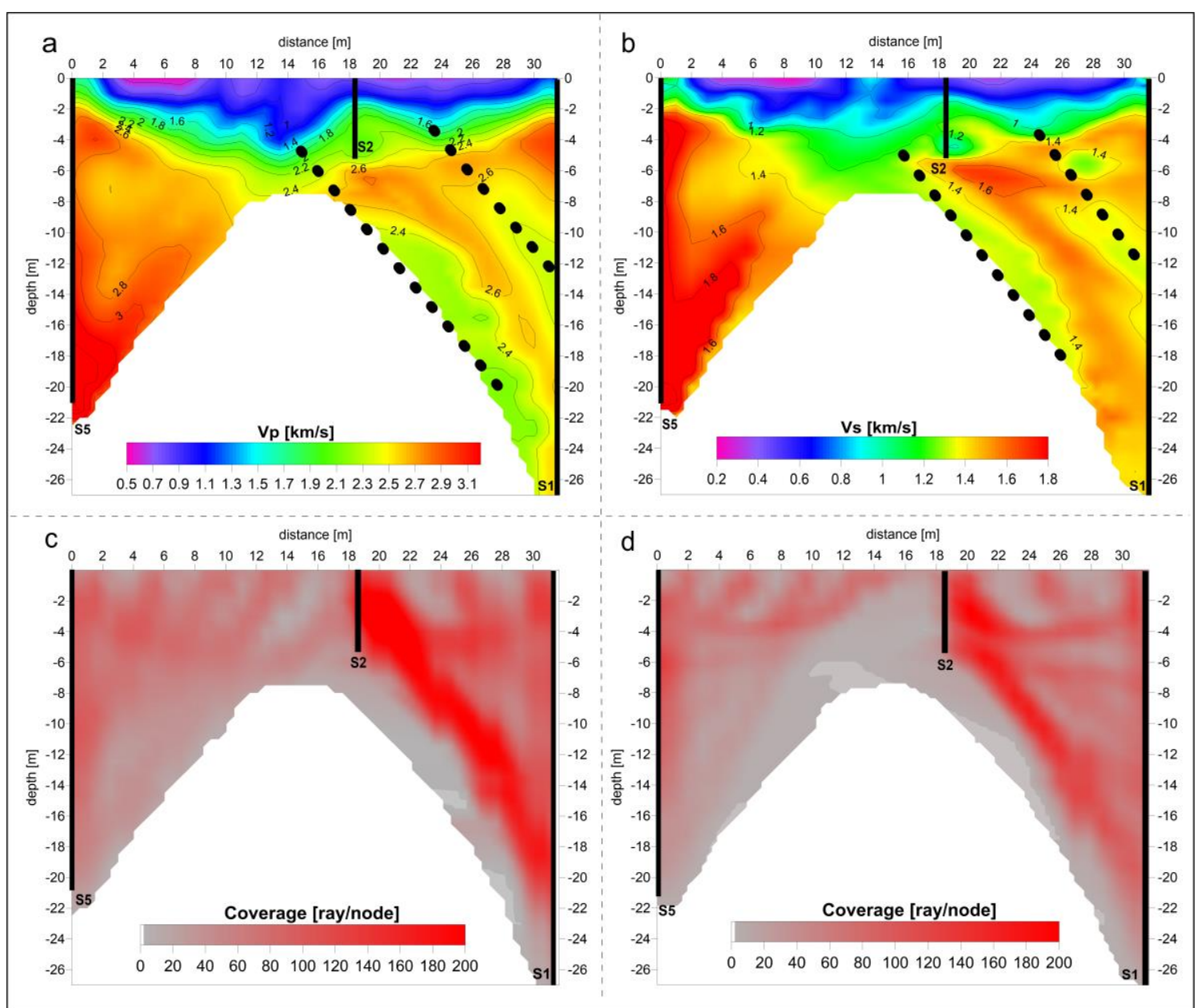

Figure 6. Results of the cross-hole seismic tomography: P- (a) and SH- (b) velocity sections; $\mathrm{P}(\mathrm{c})$ and $\mathrm{S}(\mathrm{d})$ ray coverage sections. The black dashed lines refer to the probable orientation of the $\mathrm{K} 4$ fracture system. 


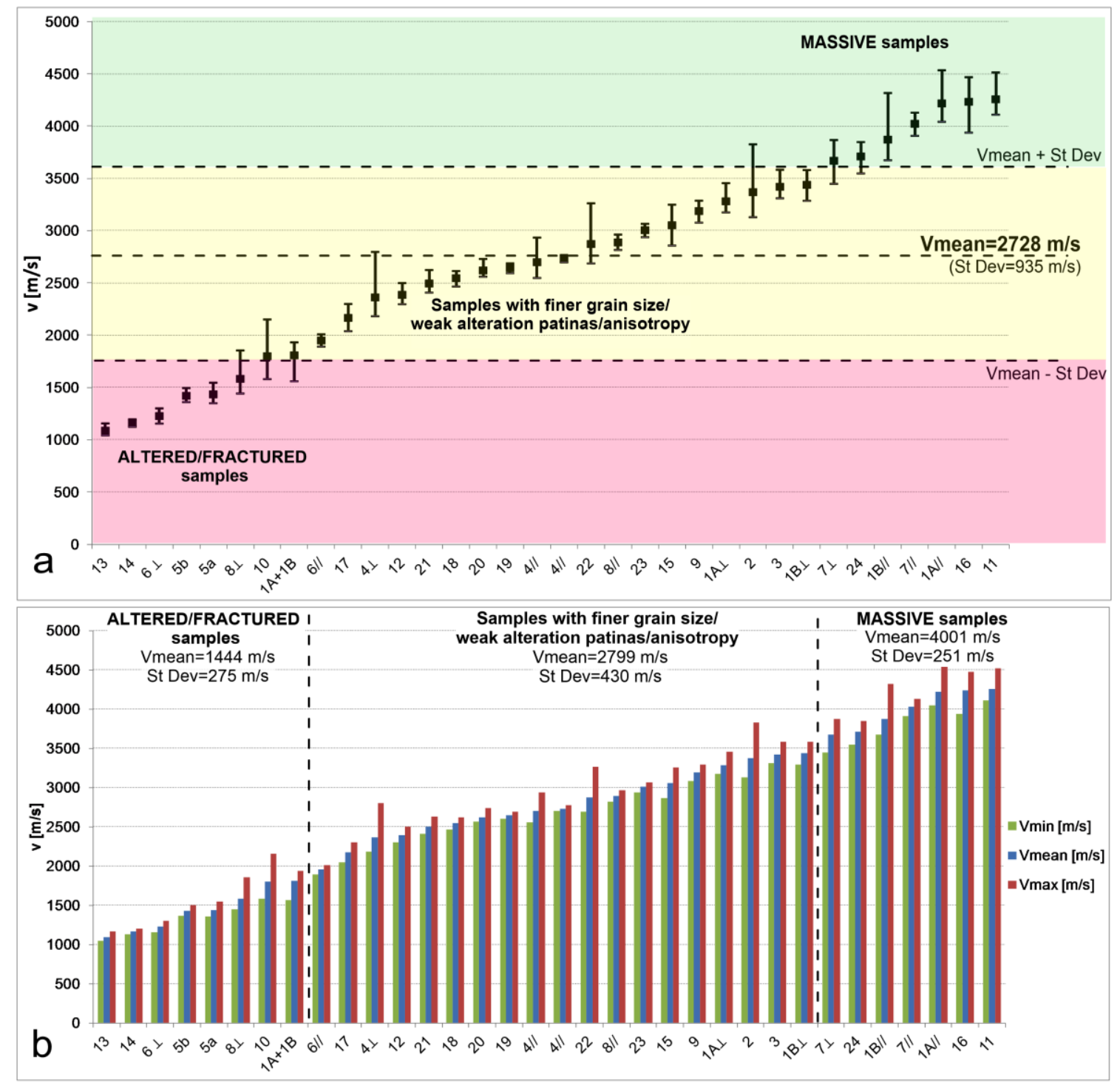

Figure 7. Mean ultrasonic pulse velocities plotted in ascending order (a). Horizontal lines mark the limits between the three classes described in the text. Histogram of the same results (b) with indication of the mean velocity value and standard deviation for each class. 


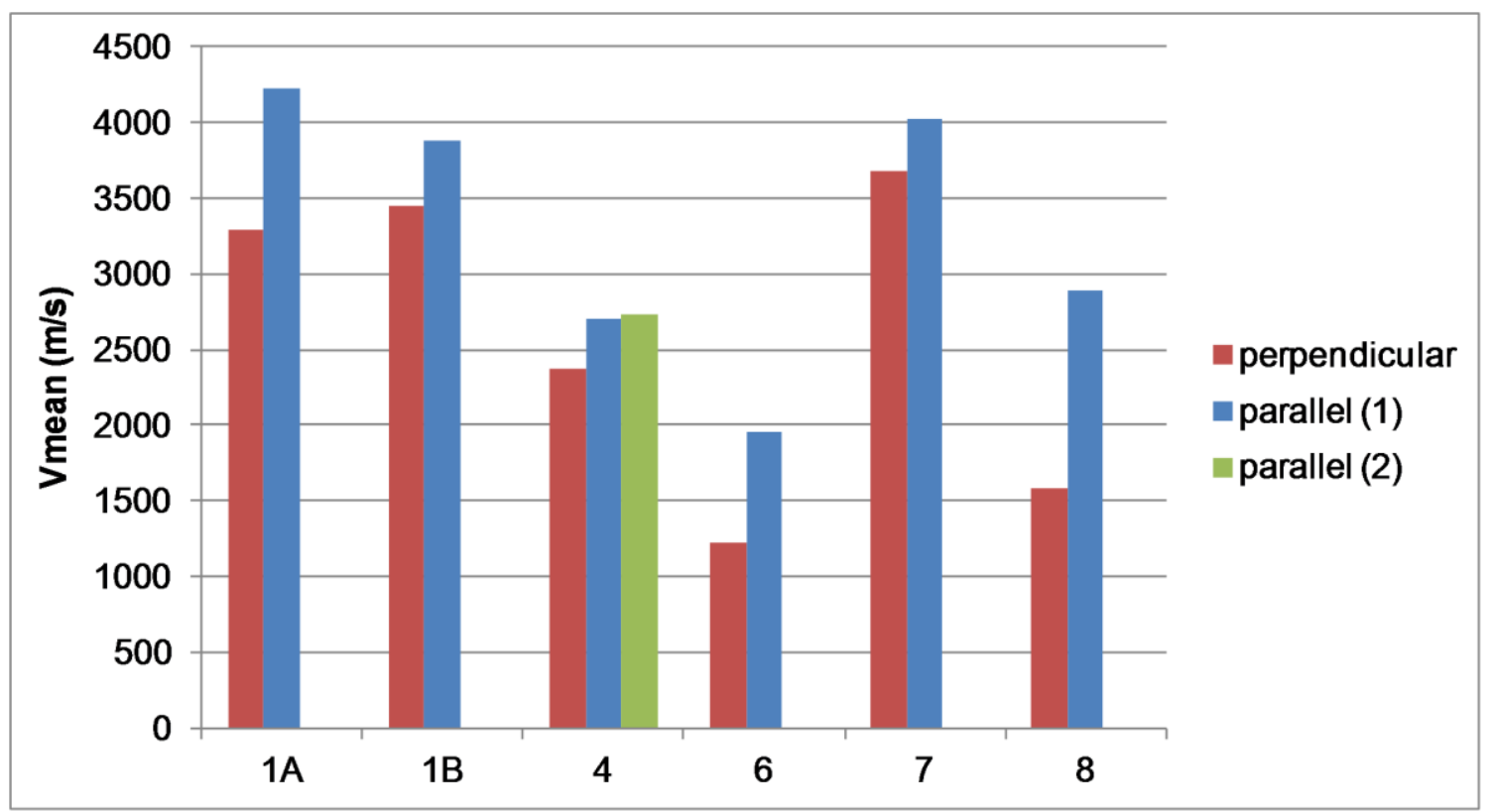

Figure 8. Mean ultrasonic pulse velocities recorded on anisotropic samples. The red columns refer to the mean velocity measured perpendicularly to the planar slight foliation, blue columns are the velocity in a parallel direction. Sample 4 was investigated in both the direction parallel to the planar anisotropy. 


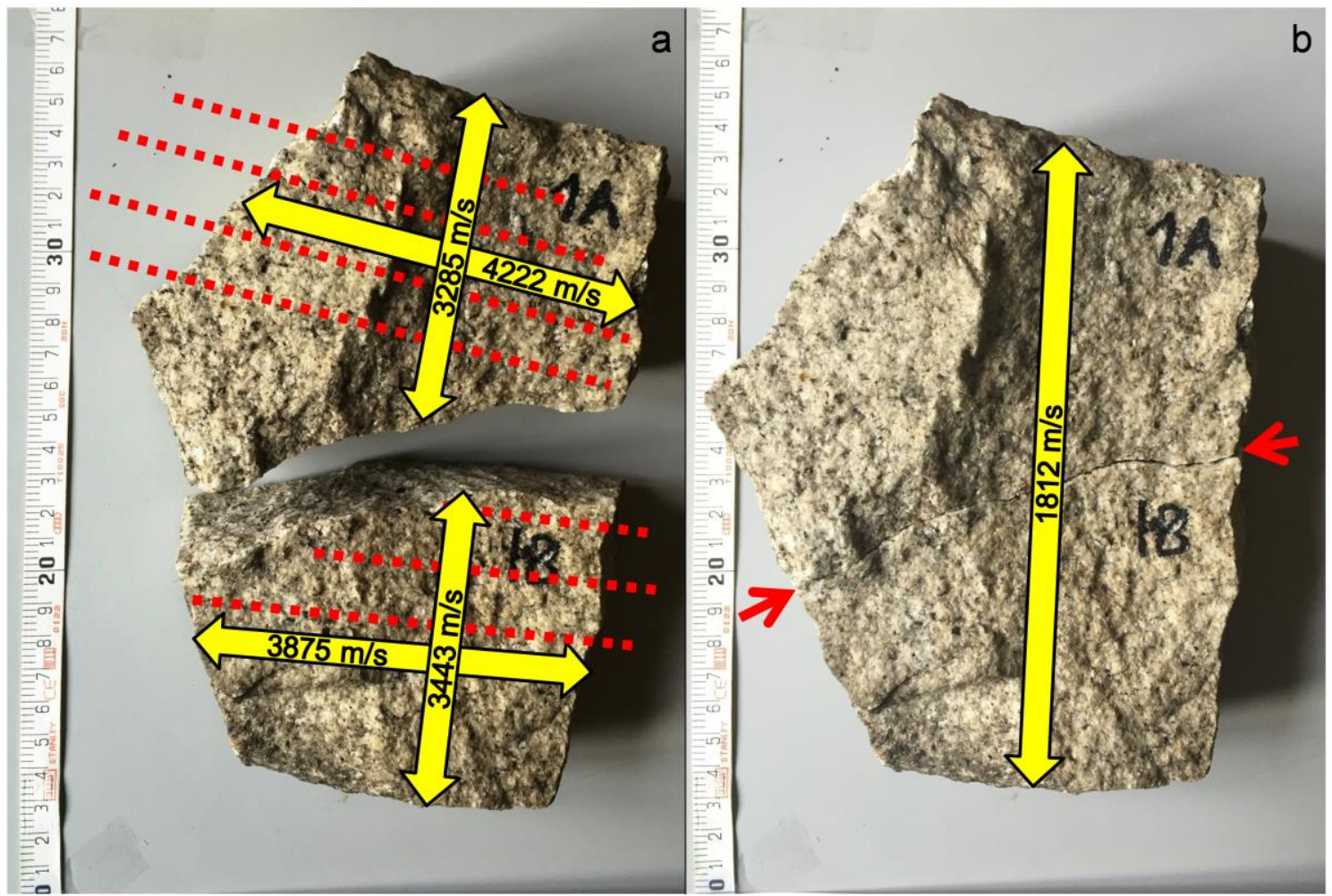

Figure 9. In (a) mean ultrasonic pulse velocities recorded on sample 1A and 1B parallel and perpendicularly to the planar anisotropy (dashed traces in red). Measurement on the reconstructed original sample in (b). 

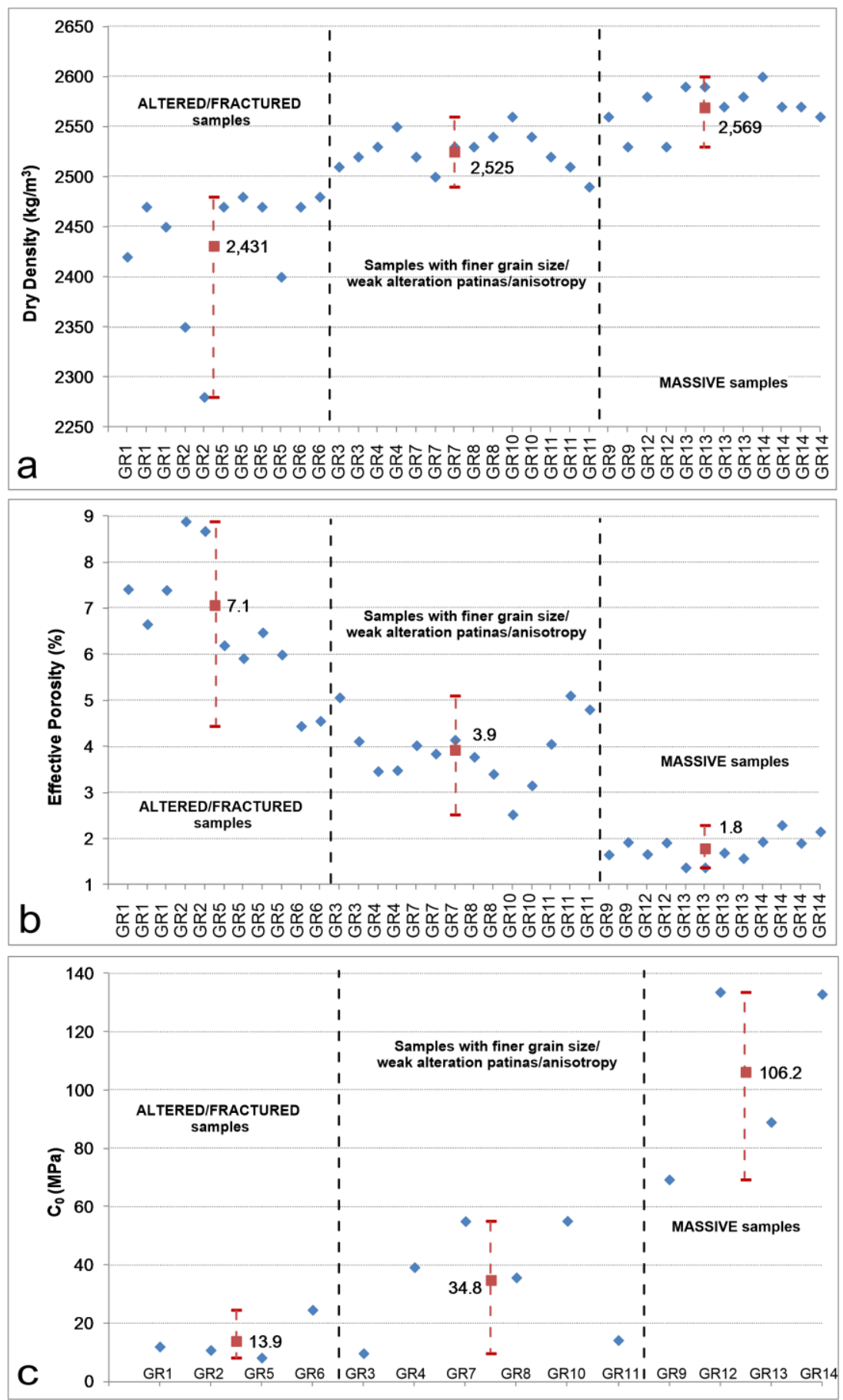

Figure 10. Physical and mechanical parameters characterizing the three macroscopic classes of granites collected in the field: (a) Dry Density, (b) Effective Porosity and (c) Uniaxial compressive strength. Blue diamonds are the measurements on each sample, red squares refer to the mean value of the macroscopic class. 


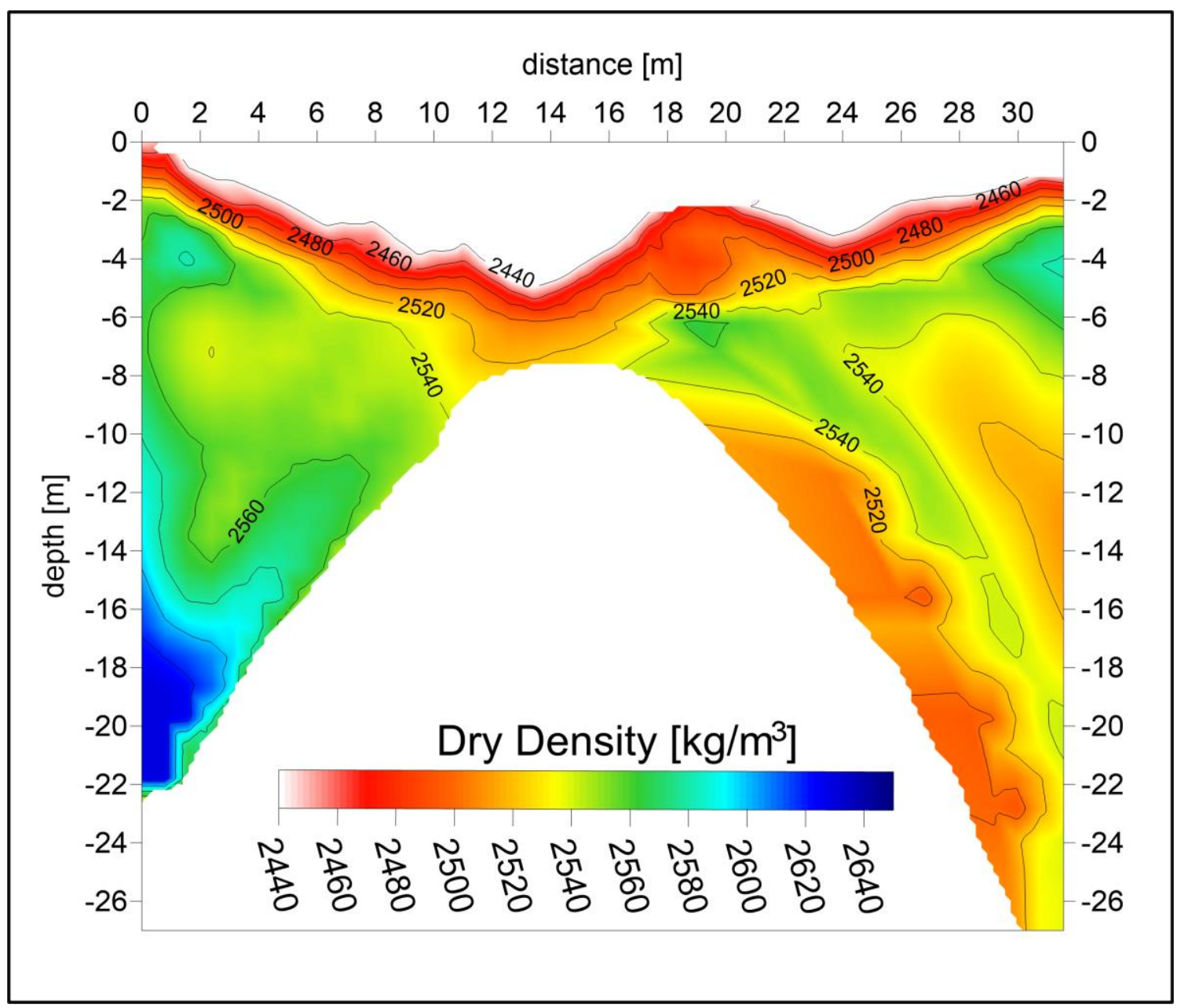

Figure 11. Density section of the granitic rock mass extracted from the correlation between density and ultrasonic pulse velocity, modified from Vasconcelos et al. (2008). The shallower layer of top soil was omitted in the computation in order to focus on granite physical properties. 